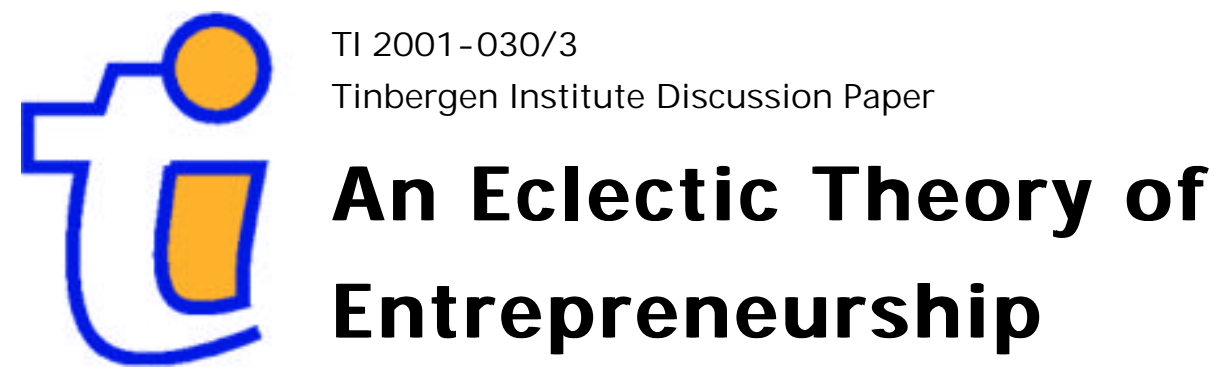

Ingrid Verheul

Sander Wennekers

David Audretsch

Roy Thurik 


\section{Tinbergen Institute}

The Tinbergen Institute is the institute for economic research of the Erasmus Universiteit Rotterdam, Universiteit van Amsterdam and Vrije Universiteit Amsterdam.

\section{Tinbergen Institute Amsterdam}

Keizersgracht 482

1017 EG Amsterdam

The Netherlands

Tel.: $\quad+31 .(0) 20.5513500$

Fax: $\quad+31 .(0) 20.5513555$

\section{Tinbergen Institute Rotterdam}

Burg. Oudlaan 50

3062 PA Rotterdam

The Netherlands

Tel.: $\quad+31 .(0) 10.4088900$

Fax: $\quad+31 .(0) 10.4089031$

Most recent TI discussion papers can be downloaded at http:// www.tinbergen.nl 


\title{
An eclectic theory of entrepreneurship: policies, institutions and culture
}

\section{Ingrid Verheul, Sander Wennekers, David Audretsch and Roy Thurik}

\author{
EIM Business and Policy Research \\ P.O. Box 7001 \\ 2701 AA Zoetermeer \\ The Netherlands \\ Tel. +31793413634 \\ ive@eim.nl, awe@eim.nl and rth@eim.nl \\ Centre for Advanced Small Business Economics \\ Faculty of Economics \\ Erasmus University Rotterdam \\ P.O. Box 1738 \\ 3000 DR Rotterdam \\ The Netherlands \\ Tel. +31104081398 \\ Fax. +31104089146 \\ verheul@few.eur.nl and thurik@few.eur.nl \\ Institute for Development Strategies \\ Indiana University \\ SPEA 201 \\ 1325 E. Tenth Street \\ Bloomington, Indiana 47405-1701 \\ Tel. 812-855-6766 \\ Fax. 812-855-0184 \\ daudrets@indiana.edu
}

Version: March 2001 (framework_2d.doc)

JEL-code: M13 (entrepreneurship), L50 (regulation and industrial policy; general), L11 (production, pricing, and market structure; size and size distribution of firms), L16 (industrial organization and macroeconomics; macroeconomic industrial structure)

Keywords: entrepreneurship, culture, institutions, policy

Acknowledgement: the present paper is the outcome of a research partnership between the School for Public and Environmental Affairs (SPEA) at Indiana University, the Faculty of Economics at Erasmus University Rotterdam and EIM Business and Policy Research in Zoetermeer. An early version of the present paper has been read at the RENT XIV Conference in Prague, November 2000. Ingrid Verheul acknowledges financial support of the VSB Fund Schiedam and the Trust Fund Rotterdam. The authors would like to thank Martin Carree and Lorraine Uhlaner for comments on an earlier version of the present paper. The present paper will also appear as a research report of EIM Policy and Business Research.

Correspondence: verheul@few.eur.nl and awe@eim.nl 


\section{Abstract}

The level of entrepreneurship differs considerably across countries and periods. Both the causes and consequences of entrepreneurship are a matter of extensive scientific debate as well as of great policy importance. A high level of entrepreneurial activity is assumed and shown to contribute to innovative activities, competition, economic growth and job creation. The present paper deals with the determinants of entrepreneurship. An eclectic theory of entrepreneurship is introduced. This eclectic theory provides an integrated framework, drawing on disparate strands of literature, to create a better understanding of the different role that entrepreneurship plays in different countries and time periods. This framework is designed to guide future empirical research in this area and to provide insights for policymakers striving to promote entrepreneurship.

Our eclectic theory focuses not only on the country level of analysis but is also linked to the level of individual occupational choices. Accordingly, the analysis is not confined to economics but also draws upon insights from psychology and sociology. The starting point of the analysis is the distinction between the supply side and the demand side of entrepreneurship. Key elements of the supply side are the demographic composition of the population, the resources and abilities of individuals and their attitudes towards entrepreneurship, i.e., their preferences. The demand side represents the opportunities for entrepreneurship. Entrepreneurial opportunities are influenced by the advent and maturation of new technologies, by the differentiation of consumer demand and by the industrial structure of the economy. In making their occupational choice between wage-employment and business ownership individuals assess - at least implicitly - the potential financial and non-pecuniary rewards and risks, based on their perception of opportunities and their personal characteristics.

Next to the distinction between demand and supply sides and a description of the process of occupational choice, attention is paid to a discrepancy between actual and equilibrium rates of entrepreneurship. The role policy measures play is dealt with extensively as well as the pervasive but difficult to establish role of culture. 


\section{Introduction}

There is very little that generates consensus in the field of entrepreneurship. When it comes to defining or measuring entrepreneurship, scholars have proposed a broad array of definitions and measures (Hébert and Link, 1989; Van Praag, 1999). Similarly, the origins and determinants of entrepreneurship span a wide spectrum of theories and explanations (Brock and Evans, 1989; Carree, 1997; Carree, Van Stel, Thurik and Wennekers, 2001; Gavron, Cowling, Holtham and Westall, 1998; OECD, 1998a). Finally, the impact of entrepreneurship on economic development is controversial (Baumol, 1990; Thurik, 1996; Audretsch and Thurik, 2000 and 2001 and Carree, Van Stel, Thurik and Wennekers, 2001).

Despite the lack of consensus with respect to different aspects of entrepreneurship scholars appear to agree that the level of entrepreneurial activity varies systematically both across countries and over time (Rees and Shah, 1986; Blanchflower, 2000; Blanchflower and Meyer, 1994; De Wit and Van Winden, 1989). In terms of the impact of entrepreneurship, the influential Employment Outlook of the OECD recently concluded that, "Self-employment has become a significant source of job growth in many OECD countries. In several it has recently grown considerably faster than civilian employment as a whole - notably in Canada and Germany. The recent picture contrasts with the 1970s, which saw the share of self-employment in total employment fall in the majority of countries. Self-employment is also an important source of entrepreneurship and small business growth - bringing with it a potential for longer-term employment growth" (OECD, 2000, p. 155).

Scholars also tend to agree that the 1970 s served as a turning point, when entrepreneurship rates reversed their long-term downward trend (Blau, 1987; Acs and Audretsch, 1993; Acs, Carlsson and Karlsson, 1999; Carree and Thurik, 2000a; Carree, Van Stel, Thurik and Wennekers, 2001). This sudden and pervasive shift has perplexed the community of scholars as well as policy makers. Since the beginning of the twentieth century large corporations were seen as the sole and most powerful engine of economic and technological progress. The large corporation was thought to have both superior production efficiency as well as innovative efficacy. The continuous decline in the number of small firms in the Western economies and the alleged successes of the Eastern European centrally planned economies, combined with the impressive domination of American corporate giants, such as IBM, U.S. Steel and General Motors, reinforced these conclusions. As Teece (1993) and Chandler (1990) emphasize, the exploitation of economies of scale and scope were considered to be the driving force of economic development. The post-war era was characterized by relatively well-defined technological trajectories, stable demand, and seemingly clear advantages of diversification. Audretsch and Thurik (2001) characterize this period as one where stability, continuity and homogeneity were the cornerstones they label as the managed economy. Small business was considered to be a vanishing breed. Preserving small business had more to do with democratic and political values than with economic efficiency.

In fact, as the fall of the Berlin Wall made clear, the centrally planned eastern economies, built around economic concentration and the exploitation of scale economies, failed and ultimately disappeared. But times have also changed for the Western economies. Large firms have been subjected to waves of downsizing and restructuring and entrepreneurship has been (re)-discovered (Carree, 1997; Gavron, Cowling, Holtham and Westall, 1998; Thurik, 1999; Wennekers and Thurik, 1999). In the 1980s, careful systematic empirical evidence documented the shift in economic activity that was taking place away from large firms to small, predominantly young enterprises. While it is clear that such a shift has taken place, it is less clear why and what the implications are. The goal of this paper is to provide new insights into the resurgence of entrepreneurship in the western world. In section two we first discuss the complex and multi-dimensional phenomenon of entrepreneurship and its consequences for measurement. In section three we present a new analytical framework for conceptualizing the underlying entrepreneurial forces. Section four outlines demand side issues, such as technology, globalization, economic development and industrial structure. Section five 
presents key supply-side factors, including population growth and density, age structure, immigration, women participation, unemployment and income levels and disparity. Section six covers the individual decision making process whereby opportunities, resources, abilities, personality characteristics and preferences are the input factors of a person's risk-reward profile. Section seven discusses the role of a possible discrepancy between actual and equilibrium rates of entrepreneurship. Section eight addresses the role of government intervention through linking policy to the other determinants of entrepreneurship. Section nine explains the pervasive influence of culture and section ten provides a conclusion.

\section{Definitions and measurement of entrepreneurship}

Comparing the level of entrepreneurship across nations is difficult for several reasons. First, there is no generally accepted definition of entrepreneurship (OECD, 1998a; Van Praag, 1999; Lumpkin and Dess, 1996; Bull and Willard, 1993). Entrepreneurship is a multidimensional concept, the definition of which depends largely on the focus of the research undertaken. An entrepreneur can fulfil different functions (Fiet, 1996). Hébert and Link (1989) distinguish between the supply of financial capital, innovation, allocation of resources among alternative uses and decision-making. They use the following definition of an entrepreneur which encompasses the various functions: "the entrepreneur is someone who specializes in taking responsibility for and making judgmental decisions that affect the location, form, and the use of goods, resources or institutions" (Hébert and Link, 1989, p. 213). Wennekers and Thurik (1999) give an alternative (more 'Schumpetarian') definition in which they focus on the perception of new economic opportunities and the subsequent introduction of new ideas in the market. These definitions from the world of economics differ from those in the management world. In their description of the difference between entrepreneurs and managers, Sahlman and Stevenson (1991, p. 1) use the following definition: "entrepreneurship is a way of managing that involves pursuing opportunity without regard to the resources currently controlled. Entrepreneurs identify opportunities, assemble required resources, implement a practical action plan, and harvest the reward in a timely, flexible way".

Second, and related to the first argument, measurement and comparison of the level of entrepreneurship for different time periods and countries is complicated by the absence of a universally agreed upon set of indicators (OECD, 1998a). One can have a static or a dynamic perspective (Wennekers, 1997, p. 185). The so-called self-employment or business ownership rate is an important static indicator of the level of entrepreneurship (EIM/ENSR, 1995). In this paper we will use the terms business ownership and selfemployment as equivalent to entrepreneurship. The term self-employment refers to people who provide employment for themselves as business owners rather then seeking a paid job. Alternatively, the focus can be on the number of small- and medium-sized enterprises in a country. On the other hand, the dynamic perspective focuses on the so-called nascent and start-up activity, as well as on the net entry rate and the turbulence rate (total of entry and exit).

In the static perspective of self-employment and business ownership two definitions can be distinguished (EIM/ENSR, 1995). The first definition refers to people leading an unincorporated business. These people usually draw no salary but use the profits of the enterprise to cover personal expenses. They have full personal liability for the conduct of the business. The second definition concerns owner-managers who gain a share of the profits as well as a salary from an incorporated business. These entrepreneurs run a risk equal to his/her share of the invested capital in the business.

In some countries, e.g., France, the Netherlands and the United Kingdom, only the first category is considered self-employed, whilst in others, e.g., Germany, Denmark, Ireland, Portugal and Spain, the second category is also included in self-employment statistics. For the present paper use is made of a harmonized database including entrepreneurship figures for 23 OECD countries for the period 1972-1998 (Thurik, 1999; Audretsch, Carree, Van Stel and Thurik, 2000). Within this data set entrepreneurship is defined broadly, 
including the owners of both incorporated and unincorporated businesses, but excluding the so-called unpaid family workers and wage-and-salary workers operating a side-business as a secondary work activity (Carree, Van Stel, Thurik and Wennekers, 2001, p. 57-58).

Table 1: Entrepreneurship as a percentage of the labor force in 23 OECD countries

\begin{tabular}{|c|c|c|c|c|c|c|c|c|}
\hline & \multicolumn{2}{|c|}{ level } & \multicolumn{2}{|c|}{ growth } & \multicolumn{4}{|c|}{$\begin{array}{l}\text { country percentage in total business } \\
\text { owners }\end{array}$} \\
\hline & 1972 & 1984 & 1998 & $1972-84$ & 1984-98 & 1972 & 1984 & 1998 \\
\hline Austria & 9.3 & 6.5 & 8.0 & -2.8 & 1.5 & 0.96 & 0.58 & 0.69 \\
\hline Belgium & 10.5 & 10.2 & 11.9 & -0.3 & 1.7 & 1.35 & 1.13 & 1.15 \\
\hline Denmark & 8.2 & 6.6 & 6.4 & -1.6 & -0.2 & 0.68 & 0.48 & 0.40 \\
\hline Finland & 6.6 & 6.6 & 8.2 & 0.0 & 1.6 & 0.49 & 0.45 & 0.46 \\
\hline France & 11.3 & 9.8 & 8.5 & -1.5 & -1.3 & 8.40 & 6.31 & 4.92 \\
\hline Germany (West)* & 7.6 & 6.8 & 8.5 & -0.8 & 1.7 & 7.05 & 5.20 & 7.56 \\
\hline Greece & 16.1 & 17.7 & 18.6 & 1.6 & 0.9 & 1.78 & 1.83 & 1.84 \\
\hline Ireland & 6.9 & 8.0 & 11.2 & 1.1 & 3.2 & 0.26 & 0.28 & 0.41 \\
\hline Italy & 14.3 & 16.5 & 18.2 & 2.2 & 1.7 & 9.56 & 9.77 & 9.52 \\
\hline Luxembourg & 10.7 & 8.3 & 5.9 & -2.4 & -2.4 & 0.05 & 0.04 & 0.03 \\
\hline The Netherlands & 10.0 & 8.1 & 10.4 & -1.9 & 2.3 & 1.99 & 1.38 & 1.80 \\
\hline Portugal & 11.3 & 10.6 & 15.2 & -0.7 & 4.6 & 1.38 & 1.28 & 1.69 \\
\hline Spain & 11.8 & 11.3 & 13.0 & -0.5 & 1.7 & 5.28 & 4.20 & 4.75 \\
\hline Sweden & 7.4 & 7.2 & 8.2 & -0.2 & 1.0 & 0.99 & 0.84 & 0.78 \\
\hline United Kingdom & 7.8 & 8.6 & 10.9 & 0.8 & 2.3 & 6.70 & 6.24 & 7.04 \\
\hline Iceland & 11.1 & 9.1 & 13.2 & -2.0 & 4.1 & 0.04 & 0.03 & 0.04 \\
\hline Norway & 9.7 & 8.7 & 7.1 & -1.0 & -1.6 & 0.56 & 0.47 & 0.36 \\
\hline Switzerland & 6.6 & 6.8 & 9.1 & 0.2 & 2.3 & 0.80 & 0.67 & 0.81 \\
\hline USA & 8.0 & 10.4 & 10.3 & 2.4 & -0.1 & 24.17 & 31.91 & 31.90 \\
\hline Japan & 12.5 & 12.6 & 10.0 & 0.1 & -2.6 & 22.04 & 19.96 & 15.10 \\
\hline Canada & 7.9 & 10.0 & 14.1 & 2.1 & 4.1 & 2.50 & 3.44 & 4.92 \\
\hline Australia & 12.6 & 16.0 & 15.5 & 3.4 & -0.5 & 2.50 & 3.06 & 3.24 \\
\hline New Zealand & 10.2 & 11.0 & 14.2 & 0.8 & 3.2 & 0.45 & 0.47 & 0.59 \\
\hline weighted average & 9.8 & 10.6 & 10.9 & 0.8 & 0.3 & & & \\
\hline
\end{tabular}

total business owners in thousands

29,390

37,430

44,927

* The data for Germany refer to West Germany for the period 1972-1990

Source: EIM: COMParative Entrepreneurship Data for International Analysis (COMPENDIA 2000.1)

Table 1 shows that the countries with the lowest rate of entrepreneurship are Luxembourg, Denmark, Norway, Austria, Sweden and Finland. For these countries, several of which are Scandinavian, the rate of business ownership is below $8.5 \%$ in $1998^{1}$. By comparison, the weighted sample average in 1998 is approximately $11 \%$. By contrast, in four countries, Greece, Italy, Portugal and Australia, the business ownership rate exceeds $15 \%$. Note that the majority of these countries is Mediterranean ${ }^{2}$. Taken as a whole

\footnotetext{
1 The Scandinavian countries all have at least several of the following characteristics that often go along with low business ownership rates: a high per capita income, high female labor participation rates, low income disparity, a large scope of the public sector and a relatively low degree of dissatisfaction with life. See Wildeman et al. (1999) and Henrekson (2000).

${ }^{2}$ Greece, Portugal and also Spain have a relatively low per capita income, implying a traditional industrial structure, and their populations show a relatively high degree of dissatisfaction. Italy is characterized by a low per capita income in Southern Italy and a specific industrial structure in Northern Italy (industrial districts with an emphasis on small family businesses).
} 
the number of business owners in the 23 countries grew from about 29 million in 1972 to about 45 million in 1998. The proportional growth of the labor force has been lower in this period so that the rate of business ownership increased from $10 \%$ to $11 \%$.

Clearly, the United States is the country with the highest number of business owners: about $32 \%$ of the total 45 million business owners in the 23 countries in 1998 are situated within the United States, about the same percentage as in 1984. Countries that increased in business ownership rate by more than 3 percentage points in the period of 1984 through 1998 include Ireland, Canada, New Zealand, Portugal and Iceland. The former three countries experienced a growth of the business ownership rate in the period prior to 1984 . There are four countries suffering a decline in the business ownership rate in both periods: Denmark, France, Luxembourg and Norway. Although Japan only had a decline in business ownership in the second period (1984-1998), this decline is particularly noteworthy since its share in total business owners dropped from more than $20 \%$ in 1972 to $15 \%$ in 1998 .

Focusing on enterprises instead of business owners SMEs can be defined as all private enterprises (excluding agriculture, hunting and fishing) employing less than 250 employees $^{3}$. Harmonized data for the European Union are available from 1988 onwards (KPMG/ENSR, 2000, p. 16), but for individual countries longer time series based on national definitions may exist. Several size-classes can be distinguished: micro enterprises (less than 10 employees, including self-employed without employees); small enterprises (10-49 employees) and medium-sized enterprises (50-249 employees).

Data of dynamic indicators of entrepreneurship are scarce. Recently for the Netherlands, the USA, the UK and Germany harmonized data for entry and exit in the period from 1972 through 1997 have been collected. For individual countries longer time series based on national definitions may exist.

When measuring entrepreneurship it is possible to identify several (additional) aspects of entrepreneurship, however these are beyond the scope of the current paper. They include gender, ethnicity, part-time entrepreneurship as a primary occupation and having a side-business as a secondary work activity, unpaid family workers and intrapreneurship. Regarding the last dimension it can be said that entrepreneurial activity not only takes place in small firms, but that it can also be present in large organizations. Entrepreneurship not only occurs in the form of small firms, but also in the form of corporate entrepreneurship, new ideas and responsibilities implemented in existing organizations (Stopford and Baden-Fuller, 1994 and Wennekers and Thurik, 1999).

\section{Determinants of entrepreneurship: a framework}

The present study deals with the factors determining the level of entrepreneurship. A broad range of determinants explains the level of entrepreneurship, including economic and social factors. Moreover, it is generally accepted that policy measures can influence the level of entrepreneurship (Storey, 1994 and 1999 and EZ, 1999). The government can exert influence on entrepreneurship in different ways; directly through specific measures and indirectly through generic measures. For example, when stipulating a competition policy, the government can influence the market structure and (indirectly) the number and type of entrepreneurial opportunities. In this section a framework is presented for understanding the various influences of policy measures on entrepreneurship. In the succeeding sections this framework will be developed in more detail.

Several studies have been conducted to assess and explain the level of entrepreneurship (Reynolds, Hay and Camp, 1999; EIM/ENSR, 1996; Carree, Van Stel, Thurik and Wennekers, 2001; Acs, Audretsch and Evans, 1994). Capturing the concept of entrepreneurship is difficult due to the diversity of statistical

\footnotetext{
${ }^{3}$ In some countries, most notably the Netherlands, SMEs are defined to be enterprises employing less than 100 employees.
} 
definitions and theoretical perspectives. The determinants of entrepreneurship can be categorized according to the disciplinary approach, the level of analysis, the discrimination between demand and supply factors and a distinction between influences on the actual and equilibrium rate of entrepreneurship.

Discussion of the determinants of entrepreneurship cannot be confined to one discipline; psychology studies have focused on motives and character traits of (potential) entrepreneurs, sociological studies have focused on the (collective) background of entrepreneurs (margination theory), economic studies have focused on the impact of the economic climate, including scarcity and opportunity costs and yields, and technological developments on entrepreneurial activity and the demographic perspective focuses largely on the impact of the demographic composition on entrepreneurship. From a regulatory perspective, the government can influence entrepreneurship both directly through support policies or establishment legislation and indirectly through policies not directly aimed at influencing the level of entrepreneurship (De Koning and Snijders, 1992; Storey, 1994 and 1999; KPMG/ENSR, 2000 and Audretsch and Thurik, 2001).

The determinants of entrepreneurship can also be studied according to level of analysis. A distinction can be made between the micro, meso and macro level of entrepreneurship. The objects of study tied to these levels of analysis, are the individual entrepreneur or business, sectors of industry and the national economy, respectively. Studies at the micro level focus on the decision-making process by individuals and the motives of people to become self-employed. See Blanchflower (2000) for a review of studies. Research into the decisions of individuals to become either wage- or self-employed focuses primarily on personal factors, such as psychological traits, formal education and other skills, financial assets, family background and previous work experience (Van Praag, 1996; De Wit and Van Winden, 1991; Evans and Leighton, 1989b). Studies at the meso level of entrepreneurship often focus on market-specific determinants of entrepreneurship, such as profit opportunities and opportunities for entry and exit (Bosma, Zwinkels and Carree, 1999 and Carree and Thurik, 1996). The macro perspective tries to aggregate the arguments at the micro and meso level and focuses on a range of environmental factors, such as technological, economic and cultural variables (Noorderhaven, Wennekers, Hofstede, Thurik and Wildeman, 1999; Carree, Van Stel, Thurik and Wennekers, 2001) as well as government regulation (OECD, 1998a). The present study focuses mainly on the country level of analysis, but attempts to explicitly link the country level to the individual level.

The level of entrepreneurship in a particular country can be explained making a distinction between the supply side (labor market perspective) and the demand side (product market perspective; carrying capacity of the market) of entrepreneurship (Bosma, Zwinkels and Carree, 1999). Elsewhere this distinction is sometimes referred to as that between push and pull factors (Vivarelli, 1991). The demand side of entrepreneurship represents the opportunities for entrepreneurship. It can be viewed from a consumers' and a firms' perspective. Within the first perspective, diversity of consumer demand is important. The greater this diversity, the more room is created for (potential) entrepreneurs. Within the second perspective, focus is on the industrial structure (sector structure, outsourcing, networking). The opportunities are influenced strongly by technological developments and government regulation. The supply side of entrepreneurship is dominated by the characteristics of the population, i.e., demographic composition. Key elements are the resources and abilities of individuals and their attitudes towards entrepreneurship, i.e., preferences. The cultural and institutional environment influences the supply side of entrepreneurship.

When studying the impact of different factors on entrepreneurship it is important to distinguish between the actual rate of entrepreneurship resulting from the short-term balance of supply and demand, and a long-term equilibrium rate determined by the state of economic development, i.e., technology, market structure.

Since the determinants of entrepreneurship can be studied from different perspectives, a framework to explain the role of the government is presented that incorporates different disciplinary approaches, levels of analysis, a distinction between the demand and supply side and a distinction between the actual and 
"equilibrium" level of entrepreneurship. These distinctions are depicted in Figure 1. The framework refers to both the decisions of individuals to start up a firm and the decisions of incumbent firm owners to remain in business or to exit.

\section{Figure 1: Framework of determinants of entrepreneurship}

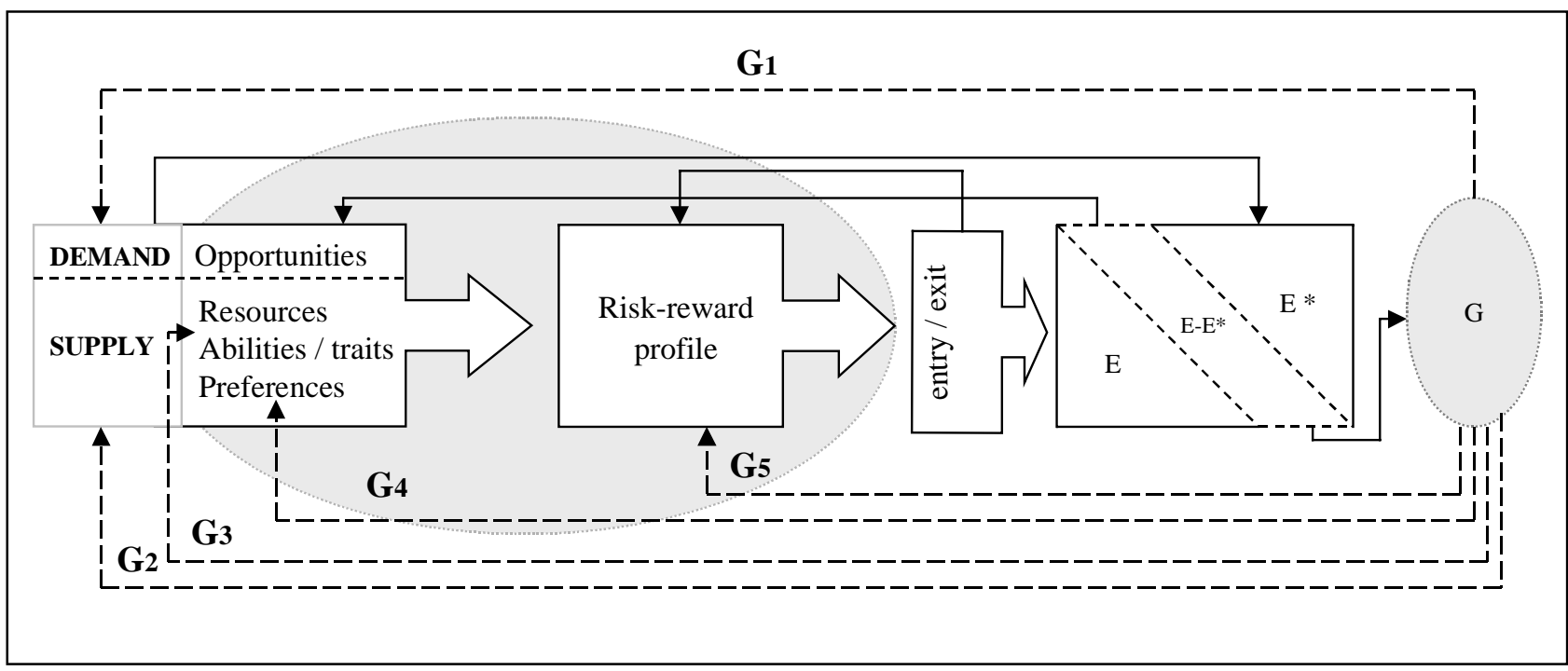

The process by which the actual rate of entrepreneurship $(E)$ is established involves both macro and micro components. At the demand side, entrepreneurial opportunities are created by the market demand for goods and services, whereas the supply side generates (potential) entrepreneurs that can seize the opportunities provided they have the resources, abilities and preferences to do so. Moreover, personality characteristics need to be in line with the entrepreneurial opportunity. The entrepreneurial decision, i.e., occupational choice, is made at the individual level, taking into account entrepreneurial opportunities and resources, ability, personality traits and preferences of the individual ${ }^{4}$. This distinction between environmental (macro) and individual (micro) characteristics is made also in the OECD Employment Outlook (2000) where it is argued that self-employment depends upon conditions as well as skills and spirit of the (potential) entrepreneur ${ }^{5}$. In the present study on the one hand we identify external resources, such as financial and technological resources and human contacts within networks. On the other hand we distinguish between different internal characteristics of the individual: ability, personality traits and preferences, i.e., values and attitudes, influencing the occupational decision.

An individual's risk-reward profile ${ }^{6}$ represents the process of weighing alternative types of employment and is based on opportunities (environmental characteristics), resources, ability, personality traits and preferences (individual characteristics) ${ }^{7}$. The occupational choices of individuals are made on the basis of their riskreward profile of entrepreneurship versus that of other types of employment, i.e., wage employment or unemployment. At the aggregate level these occupational choices materialize as entry and exit rates of entrepreneurship. Weighing alternative types of employment people can trade in their wage jobs (or

${ }^{4}$ Our model of occupational choice bears some resemblance to the entrepreneurship development framework used by Stevenson (1996), in the sense that in her model motivation, skills and opportunity factors are the key aspects of business start-ups.

${ }^{5}$ In the OECD Employment Outlook (2000) 'conditions' include access to finance, administrative burdens, taxation and social security. 'Skills' include human capital and managerial skills and 'spirit' refers to personal choice (OECD, 2000). Within our framework individual characteristics are defined broader, including the (individual) access to capital.

${ }^{6}$ The concept of 'willingness' proposed by Van Praag en Van Ophem (1995) bares resemblance to the concept of the risk-reward profile we use in this study. Van Praag and Van Ophem define willingness to start a business as "the valuation of selfemployment versus wage- or unemployment, for otherwise identical situations". They consider willingness as "dependent upon both individual preferences for the special features of self-employment as well as on the available outside options and their perceived attractiveness".

${ }^{7}$ Individual characteristics also involve demographic characteristics, such as age, gender, marital status and ethnic background. These demographic characteristics to a certain extent determine the availability resources to an individual and their abilities and preferences. 
unemployment) for self-employment, i.e., entry into entrepreneurship, they can remain within the type of employment they are currently in or they can decide, either voluntarily or involuntarily, to exit from selfemployment. Entry and exit can also impact the risk-reward profile of entrepreneurship. This is often referred to as the "demonstration effect", where the mere gulfs or dynamics of entry and exit influence the (perceived) attractiveness of self-employment, independent of existing opportunities and individual characteristics. If many people enter self-employment other people may be signaled and persuaded to start their own business without taking into consideration the possibilities and the financial and/or intellectual capital needed to successfully launch a business.

Together, both static and dynamic occupational decisions determine the actual level of entrepreneurship $(\mathrm{E})^{8}$. The actual rate of entrepreneurship may deviate from the "equilibrium" rate of entrepreneurship $\left(E^{\star}\right)$ that can be viewed as a long-term equilibrium rate resulting from demand-side forces, such as technological developments and changes in the market structure (Carree, Van Stel, Thurik and Wennekers, 2001). This "disequilibrium" (E-E*) can be restored either through market forces or government intervention. On the one hand the discrepancy between the actual and the optimal rate of entrepreneurship is expressed through a surplus or lack of entrepreneurial opportunities, leading to entry and exit of entrepreneurs, respectively. On the other hand, the government can try and link the actual and "equilibrium" rate of entrepreneurship through intervention ${ }^{9}$.

Policy intervention in the economic process should take into account both environmental conditions and individual characteristics (OECD, 2000) and can work through the different components of Figure 1. Policy measures and institutions may influence either the key determinants in the individual decision making processes, and in that way indirectly co-determine business ownership, or the mechanism itself, i.e., the manner in which these variables determine the decisions with respect to business ownership. Government policies dealing with the (de)-regulation of entry and privatization or collectivization of many services and utilities influence opportunities to start a business (see arrow G1 in Figure 1). The supply of future entrepreneurs and their characteristics can be influenced, albeit to a small extent, through immigration policy (G2). Resources and abilities, i.e., skills and knowledge, of individuals can be influenced through education, promoting the availability of capital, i.e., development of the (venture) capital market or financial support, and provision of information, through consulting or counseling (G3). Preferences of individuals are more difficult to influence. To a large extent, they are determined by cultural background and as a result are difficult to modify (OECD, 2000). The government can try to influence individual preferences by fostering an entrepreneurial culture. This can be done using the educational system and the media (G4). Moreover, fiscal incentives, subsidies, labor market regulation and bankruptcy legislation co-determine the net rewards and the risks of the various occupational opportunities (G5).

The next six sections will focus on the basic six elements of the above framework (demand side, supply side, individual decision making, actual and equilibrium rates, government intervention and culture).

\section{$4 \quad$ Demand side}

\subsection{Introduction}

Discrimination between demand and supply factors is customary when explaining the level of entrepreneurship (Blanchflower, 2000; Storey, 1994, chapter 2). Whereas the entrepreneurial decision is

\footnotetext{
${ }^{8}$ Note that different levels of analysis are linked here; the risk-reward profile shaped at the individual level determines the actual rate of self-employment at the country-level.

${ }^{9}$ In order to intervene at the national economy, it is important that the government is able or willing to perceive a deviation from the optimal rate of entrepreneurship. Moreover, independent of the magnitude of the optimal rate, the government will have its own (political) ideas about the desirable level of entrepreneurship.
} 
made at the individual level, supply and demand factors relate to a higher level of aggregation. The supply and demand side create conditions for the entrepreneurial decision made at the individual level. The demand side creates entrepreneurial opportunities through the market demand for goods and services, whereas the supply side provides potential entrepreneurs that can act upon the opportunities. The demand for entrepreneurship is determined by a combination of factors, including the stage of economic development, globalization and the stage of technological development. These factors influence the industrial structure and the (diversity in) market demand leading to opportunities for entrepreneurship. See Figure 2. The demand side factors are highly interrelated and can be considered, to a certain extent, general factors that apply to all countries. The supply of entrepreneurship is determined by the size and composition of the population, including age structure, population density and the urbanization rate, the number of immigrants and the proportion of women in the population or in the labor market. The supply side is dealt with in section 5.

\section{Figure 2: Demand side determinants of entrepreneurship}

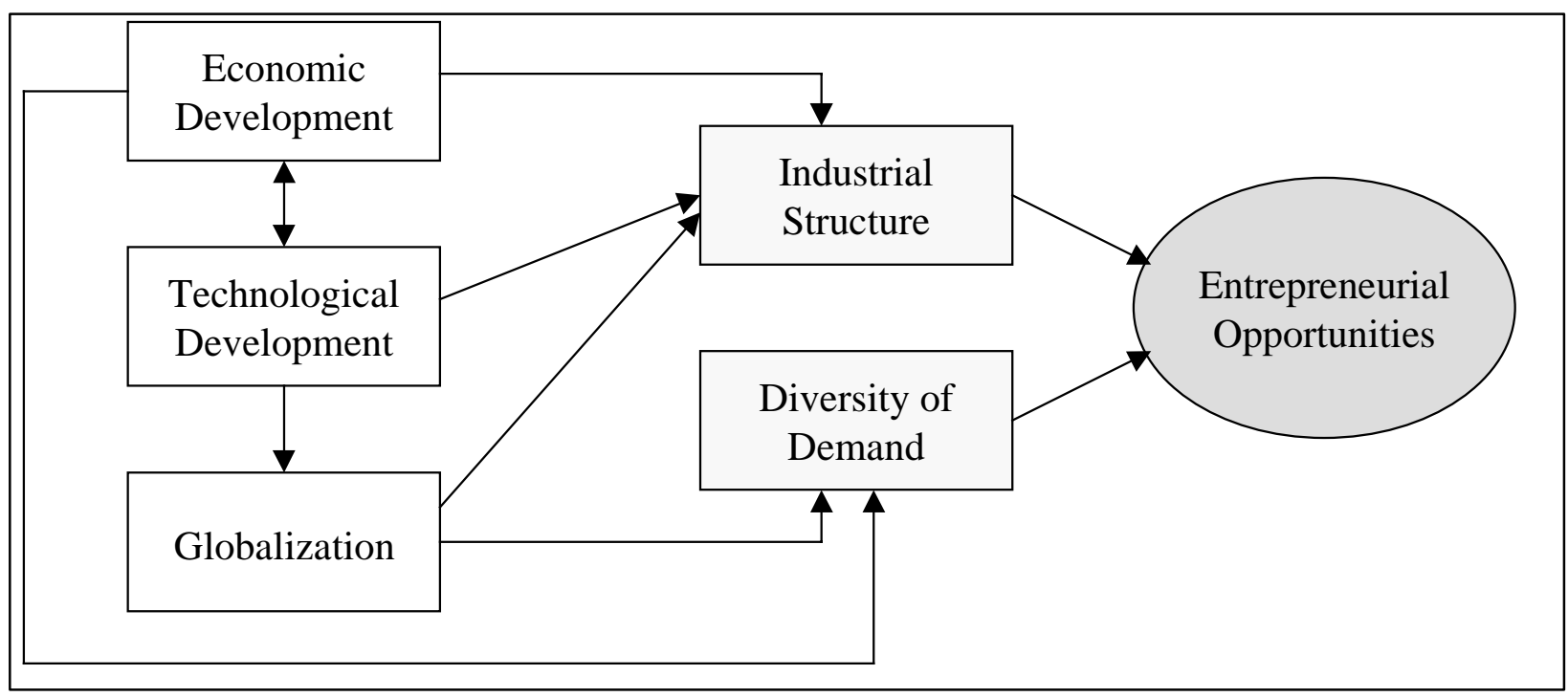

\subsection{Technological development}

A two-way relationship is assumed between technological advancement and entrepreneurship; on the one hand technological developments are often considered to be the driving force in the demand for entrepreneurship (Wennekers and Thurik, 1999), whereas, on the other hand, small firms are expected to play an important role in the development and spread of innovation (OECD, 1996). Moreover, while influencing entrepreneurship, technological development is assumed to interrelate with other demand side factors.

Contemporary technological developments, such as the application of information technology, seem to favor small-scale production through cheaper capital goods, a decreasing minimum efficient scale and possibilities for flexible specialization (Piore and Sabel, 1984; Carlsson, 1989 and Loveman and Sengenberger, 1991). Moreover, recent advances in information technology have created better access to information and communication devices that may facilitate small business ventures and enhances the competitiveness of established small businesses. The (marginal) costs of transforming information across geographic space have dramatically decreased. Information can be transferred through email, fax machines, and cyberspace (Audretsch and Thurik, 2000 and 2001). As a consequence, market-based coordination is cheaper relative to internal coordination, leading to a decline in firm size and diversification (Jovanovic, 1993). Additionally, technological advancements have induced a reallocation of resources towards new products, leading in turn 
to a more intense demand for entrepreneurship (Casson, 1995). Hence, the number of products in an early stage of their product life cycle may be expected to increase. Moreover, it is known that the number of firms tends to rise strongly in the early stages of the product life cycle (Klepper, 1996; Carree and Thurik, 2000b; Klepper and Simons, 1999). Many successful new businesses are often found within high technology sectors, such as the computer industry and biotechnology (Krugman, 1991 and OECD, 1998a).

Technological developments lead to more dynamism in the economy, as expressed by shorter product life cycles. As a consequence less advantage can be obtained from economies of scale, thus favoring small businesses. Moreover, economic dynamism entails risks that can be better absorbed by small businesses that easily adapt to new situations than static large businesses caught in their technological paradigm.

Next to these positive effects of technological developments on the level of entrepreneurship a negative effect can be distinguished. Technological developments can create barriers to entry for new firms entering specific markets as a result of high R\&D costs (EIM/ENSR, 1993 and 1996).

Technological developments can impact the level of entrepreneurship indirectly through globalization and economic development. Technological developments, such as information and communication technology and the advent of cyberspace, have resulted in information exchange and communication without boundaries. Moreover, technological developments lead to higher levels of prosperity.

\subsection{Globalization}

The impact of globalization on the level of entrepreneurship is not straightforward and can be both negative and positive. Globalization involves the integration of world markets and offers opportunities for exploiting scale. Moreover, globalization involves the disappearance of trade barriers, creating new opportunities for all firms, either large or small. As a consequence, increasing competition in international markets may have a negative impact on the survival rates of (small) businesses.

On the other hand, the risk of variability in sales caused by the increased international competition and the volatility in exchange rates, can be better absorbed by small firms adopting production technologies that permit them to adapt quickly to changes in market demand (Carree, 1997). The latter argument reveals the interrelationship between globalization and information technology. Globalization creates opportunities for small firms, provided that entrepreneurs use other or new (production) technologies, whereas information technology developments enable globalization (Audretsch and Thurik, 2000).

Additionally, the increase in international competition and the increase in cross-cultural influences, through which globalization expresses itself, has made people aware of the existence of other cultures and their characteristics through the nature and type of products and services offered. This exposure of people to foreign products, making people aware of available consumer goods from all over the world, has created new 'global' wants and needs and accordingly more diverse consumer demands. Particularly in the last decades there has been an increased diversification of consumer preferences and an increased demand for tailormade and individualized goods and services. Next to the process of globalization, expressing itself through an increase in international competition and cross-cultural influences (Acs, Audretsch and Evans, 1994) this demand for variety can be attributed to an increasing prosperity (Jackson, 1984). An increasing prosperity creates preferences for goods and services fulfilling higher needs. Accordingly, a large number of niches has been created, offering opportunities to new entrepreneurs (Wennekers, 1997). Many specialty companies have entered the market place. Moreover, flexible specialization enables small firms to respond adequately to a change in consumer demands (Loveman and Sengenberger, 1991). 


\subsection{Economic development}

In the previous sections economic development was not explicitly discussed as a determinant of entrepreneurship, although it probably has a strong indirect influence through other determinants ${ }^{10}$. The impact of economic growth on the level of entrepreneurship is however ambiguous. It appears that economic growth can either have a positive or a negative impact on the level of entrepreneurship, depending on the stage of economic development and on the intermediate factors through which economic growth exerts influence on entrepreneurship.

Various studies argue that economic development is accompanied by a decrease in the self-employment rate (Kuznetz, 1966; Schultz, 1990; Bregger, 1996). This decrease has been persistent since the Middle Ages; economic activity moved away from families towards factories (The Economist, 1999). Several arguments have been brought forward supporting a negative impact of economic growth on the level of self-employment (Carree, Van Stel, Thurik and Wennekers, 2001). Economic development is accompanied by an increase in wage levels and often by an improved system of social security. Rising real wages raise the opportunity costs of self-employment and thus make wage employment more attractive (EIM/ENSR, 1996). Fewer people are willing to leave 'secure' jobs as wages increase with economic development (lyigun and Owen, 1988). Marginal entrepreneurs may be induced to become employees and this pushes up the average size of firms (Lucas, 1978). Moreover, higher wages stimulate enterprises to work more efficiently, leading to the use of economies of scale.

On the other hand it is observed that, since the 1970s, per capita income has a positive impact on the selfemployment rate in most developed countries (Storey, 1999, p.26; Carree, Van Stel, Thurik and Wennekers, 2001). There are arguments that support this positive impact of economic growth on the level of entrepreneurship (Carree, Van Stel, Thurik and Wennekers, 2001). Recent economic development often is accompanied by the emergence of new industries. Small firms have a relative innovative advantage in high innovative industries (Acs and Audretsch, 1987). New technologies have reduced the importance of scale economies in many sectors and small firms are no longer at a disadvantage. Moreover, small firms are well equipped to implement technological advances (Carlsson, 1989). Increasing wealth leads to higher consumer needs. The demand for a variety of products and services increases and small firms are well equipped to supply these new and specialized goods. Moreover, a higher level of prosperity may lead to higher personal needs, as argued by Maslow. The higher need of self-realization is likely to be better fulfilled through selfemployment ${ }^{11}$ than working in routinized teams. The employment share of the service sector increases with per capita income and the service sector is characterized by small firm size, thus creating opportunities for entrepreneurship (EIM/ENSR, 1997). ${ }^{12}$

Technological developments and the increase in prosperity jointly effect entrepreneurship. Increasing prosperity leads both to a more differentiated demand for goods and services (more luxurious products) and a demand for new goods and services. Regarding the latter, technological developments create a supply in new goods and services and the joint effect of the supply and the demand for these new products leads to more entrepreneurship. However, the causality between the demand and supply of new goods and services is not clear. On the one hand, technological developments can lead to the supply of new goods and services and the mere exposure of people to these new products can lead to the creation of new wants, as existing goods and services can no longer satisfy consumers. On the other hand, increasing prosperity gives people the means to buy more and differentiated (new) goods. The increasing wealth and the demand of people for

\footnotetext{
${ }^{10}$ In the present paper economic development is used synonymous to prosperity and wealth.

11 Blanchflower and Oswald (1998) provide some evidence that on average entrepreneurs have a higher job and life satisfaction than employees.

12 There also seems to be a reverse causality; high or increasing levels of small business presence lead to higher economic growth (Carree and Thurik, 1998 and 1999 and Carree, van Stel, Thurik and Wennekers, 2001) or lower levels of unemployment (Audretsch and Thurik, 2000).
} 
new goods then creates incentives for businesses to fill these market niches. Technological developments enable small business owners to react to the newly created consumer demands.

\subsection{Industrial structure}

\subsubsection{The service economy}

The increase in prosperity, accompanying economic development, has affected the industrial structure of the Western world. Generally, several stages of economic development are distinguished that are each characterized by different levels of self-employment (Acs, Audretsch and Evans, 1994). In the first stage, the economy specializes in the production of agricultural products and small-scale manufacturing. In this stage there are high levels of self-employment. In the second stage, the economy shifts from an agricultural towards a more manufacturing oriented economy. This stage is characterized by increasing firm scale. In the third stage the economy shifts from manufacturing towards services, offering new opportunities for smallscale production ${ }^{13}$. At present, countries in the Western world experience an increase in the number of firms in the service sector. Most services are characterized by a relatively small average firm size, creating opportunities for self-employment (EIM/ENSR, 1997). The service sector is characterized by low initial capital requirements, thereby minimizing barriers to entry and making start-up easy.

\subsubsection{Outsourcing and spin-offs}

In the 1970s the credo was "big is beautiful". Industrialization and economic development were attributed to large businesses, exploiting economies of scale through mass-production. As of the 1980s, partly as a result of a structural crisis, large enterprises have started concentrating on 'core competencies' and 'outsourcing'. Increasingly, companies are contracting out non-core activities, such as cleaning, security and catering. The tendency of large firms to externalize activities not belonging to their core business or that are considered less profitable or more risky, creates opportunities for entrepreneurship, stimulating start-ups of both subsidiaries and new enterprises (Suarez-Villa, 1998). Closely related to outsourcing, the number of corporate ventures, spin-offs and divestments have also increased (Wennekers and Thurik, 1999). When uncertainty is high and information is imperfect, market exchange tends to be more efficient than intra-firm transactions. In a world dominated by a high degree of certainty and predictability of information, transactions within firms tended to be more efficient than market exchange. This is consistent with the well-documented increase in both vertical integration and conglomeration during the post-war period (Chandler, 1977). In the last twenty years, both of these trends have been reversed (Carlsson, 1989). Carlsson and Taymaz (1994) show that the decrease of vertical integration and conglomeration since the mid-1970s is accompanied by a decrease in mean firm size.

\subsubsection{Clustering and regional development}

Clusters, i.e., corporate relationships, involve various levels of commitment between large enterprises and small businesses. Clusters are geographically agglomerated industries, i.e., a high density of business activity, resulting in ideas and both cooperation and competition between businesses (Audretsch and Thurik, 2001). Moreover, clusters are characterized by the focus on one particular industrial activity and the fact that many small firms specialize in different phases of the production process (OECD, 1996).

\footnotetext{
${ }^{13}$ It should be born in mind that economic development has cyclical aspects because periods of economies of scale and flexible specialization alternate. Initially, a new product is produced by specialized small firms and gradually, more experience in production can lead to more product-specific knowledge and, as a consequence, to exploiting economies of scale (Carree and Thurik, 2000b).
} 
These regional industries can foster entrepreneurship in different ways. ${ }^{14}$ Within clusters R\&D is often undertaken, leading to new ideas and innovations. High technology developments are often better supported by a group of cooperating businesses than by one or several large businesses because of the opportunities to trade tacit knowledge within the cluster (through cooperation). The coordination in a cluster is in between internal and external coordination; it has the advantages of internal coordination, i.e., facilitating the trading of tacit knowledge, without the disadvantages of external coordination, i.e., high transaction costs. Moreover, informational advantages and accomplished technological developments in clusters create opportunities for small businesses. Often clusters produce spin-off firms that try to put innovative ideas into practice. Large businesses usually do not want to take the risks associated with the investment and marketing of innovative products, as these ventures tend to be costly and organizational challenging. Moreover, not only clusters that deal with high technology products and developments can stimulate new venture developments. Informal networking and relationships in general can impact the level of entrepreneurial activity (OECD, 1998a). This type of interaction between businesses is possible through the proximity of similar or like-minded industries or through fair trades and conferences, diffusing and sharing knowledge and practicing innovative ideas (Audretsch and Thurik, 2001).

As Zvi Griliches (1992) has pointed out, knowledge spillovers come from different people working on similar things. Empirical evidence supports Griliches' conjecture in identifying that knowledge spillovers are promoted in clusters of economic activity (Audretsch and Feldman, 1996 and Audretsch and Stephan, 1996). Thus, co-operation between individuals as well as between different firms generates the spillover of knowledge and new ideas. There is a large incentive for individuals and firms to interact co-operatively to create and explore new ideas that would otherwise remain undiscovered.

At first sight the mere proximity of small businesses in clusters does not directly affect the level of entrepreneurship in a country. Clustering impacts entrepreneurship through the creation of opportunities for new ventures instead of through attracting established small businesses. However, when looking more carefully, clusters enhance the competitiveness of established small businesses and thereby influencing the survival rate of these businesses. Clustering thus can have impact on the level of entrepreneurship through both entry and exit. ${ }^{15}$ Informational advantages and the accomplished technological developments in clusters create opportunities for small businesses (entry) and increase the competitiveness of established small businesses (exit). Clustering is an essential phenomenon of the 'new economy'.

\section{Supply side}

\subsection{Introduction}

The extent to which a certain population produces (potential) entrepreneurs depends on its characteristics, such as growth and spatial dispersion, demographic composition, and the level and disparity of income. In the context of the present framework the dispersion of the population is expressed through population density and urbanization rate and population composition by the age structure, the proportion of immigrants and women. These supply side factors have consequences for the likelihood of the population to become selfemployed and are dealt with in the following sections.

\footnotetext{
${ }^{14}$ Storper and Salais (1997) argue that learning processes are of central importance to the understanding of the functioning of regional economies. The diffusion of knowledge, through a collective learning process, proceeds most efficiently in an innovative milieu characterized by a high degree of openness based on personal networks that are embedded in local communities and the proximity of work, social and cultural relationships.

${ }^{15}$ When studying the impact of groups of cooperating firms, i.e. clusters, on entrepreneurship a distinction should be made between vertical and horizontal relationships between firms. In case of vertical relationships, the division between one firm internalizing part of the production chain, and two firms each specializing in different parts of the production chain, is vague. Only when different functions within the production chain are externalized, opportunities for entrepreneurship are created.
} 


\subsection{Population growth}

The pace of population growth has important consequences for the level of self-employment in a country (Bais, Van der Hoeven and Verhoeven, 1995). Countries that are characterized by a rapidly expanding population and work force are found to have a growing share of self-employed people in the work force, whereas countries experiencing low population growth are found to have a diminishing share of entrepreneurs in the labor force (ILO, 1990). However, it may not be population growth itself that is a determining factor of self-employment. Population growth can be due to natural growth, i.e., the balance of births and deaths, or to immigration. Population growth may thus involve a growing share of ethnic minorities. Ethnic origin is known to influence the choice between self-employment and paid labor (Storey, 1994). Population growth may also be accompanied by a pressure on wages, lowering the opportunity costs of selfemployment. Moreover, population growth will create a future increasing demand for goods and services. Expectations of potential entrepreneurs of future entrepreneurial opportunities are likely to stimulate start-ups (Reynolds, Hay and Camp, 1999) ${ }^{16}$.

\subsection{Population density and urbanization rate}

Evidence is mixed regarding the impact of population density, expressed through the urbanization rate, on the level of entrepreneurship. On the one hand, urban areas with high population density are able to support the growth of entrepreneurial activity because of market proximity and a business infrastructure (Brüderl and Preisendörfer, 1998). In addition, research centers and universities, often situated within urban areas, can offer an educated work force and access to innovational processes and/or products. Moreover, the establishment of businesses in a certain area is likely to attract other businesses because of the opportunities of cooperation, spillover effects and the "signaling effect"17 (Audretsch and Fritsch, 2000; OECD, 1998a, chapter 6). High population density in urban regions may be an important reason for the existence of small business in urban areas and the startup of new businesses (Reynolds et al., 1994 and Storey, 1994). On the other hand, population density and urbanization can lead to the pursuit of economies of scale, enabling firms to produce more (efficiently) for the customers that are abound. Moreover, thinly populated areas with many dispersed small villages often have many small retail stores, indicating that population density can have a negative effect on the level of business ownership (Bais, Van der Hoeven and Verhoeven, 1995).

\subsection{Age structure of the population}

The age structure of the population can have both a direct and indirect impact on the level of entrepreneurship. The direct effect implies that people of a certain age are often considered more likely to start a business. Peters, Cressy and Storey (1999) found evidence that on average younger people are less likely to be(come) self-employed. Several publications show that the probability of a person to become selfemployed increases with age (Brock and Evans, 1986; Evans and Leighton, 1989a; de Wit, 1991 and Acs, Audretsch and Evans, 1994). Evans and Leighton (1989a) show that relatively many entrepreneurs start a business in their mid-thirties and that the average age of an entrepreneur is over 40 years. Storey (1994) reports that people typically start a business when they are between 25 and 40 years old. However, recently some contrary evidence was assembled by Van Gelderen (1999), who reports that so-called nascent entrepreneurship in the Netherlands is most frequent among the age group between 25 and 34 years of age. It is unknown whether this indicates an age effect or a generation effect.

${ }^{16}$ According to Reynolds, Hay and Camp (1999) no or negative population growth should be anticipated by the national government and a shortage in a country of people who are most likely to pursue self-employment can be compensated by stimulating other groups, women or younger/older people, to become self-employed.

${ }^{17}$ The 'signaling' effect refers to the fact that the (mere) establishment of businesses in a certain area is perceived as an indication of the attractiveness of this area by other businesses. 
At the macro-level contradictory evidence exists on the relationship between age structure and entrepreneurship as well. Evans and Leighton (1989a) find that a declining age of the population has a negative effect on the level of self-employment, whereas Reynolds, Hay and Camp (1999) report that countries with more individuals in the age class of 25-44 years old have more start-ups and that the presence of so-called 'early career' individuals is an important determinant of the level of business start-ups.

Indirectly, age structure influences the level of entrepreneurship through different intermediary factors, such as psychological and social characteristics of the entrepreneur, financial resources, behavior and networks or contacts. These factors all depend on the age of the entrepreneur and co-determine entrepreneurship (Peters, Cressy and Storey, 1999).

\subsection{Immigration}

The number of immigrants in a country can either have a direct or an indirect impact on the level of entrepreneurship in a country. Indirectly, immigration is assumed to have consequences for both population growth and the age structure of the resident population because immigrant families usually have a younger age structure and more children. This may be due partly to religious and cultural values.

Next to the indirect impact of immigration, through demographic factors, immigration can also have a direct effect on the number of self-employed (Borooah and Hart, 1999; Bates, 1997). The tendency and/or ability to become self-employed differs between native people and immigrants. Immigration involves taking risks and this is also the case for entrepreneurship. Immigrants are therefore considered to have an appropriate attitude or set of mind to start a business. Moreover, entrepreneurial activities of immigrants can be stimulated or constrained by specific factors that do not apply to native people (EIM/ENSR, 1993). Ethnic minorities often have a backward position in society, because of difficulties with native behavior, language and attitudes. The participation rate of ethnic minorities in the labor market stays behind and, when they do participate, they are often situated within the 'secondary' labor market occupations (SER, 1998). One way for migrants to escape their backward position is to become an entrepreneur ${ }^{18}$.

In a study by Clark and Drinkwater (2000) it is found however that individuals who have difficulty with the language of the host country and recent immigrants are less likely to be self-employed. This can be attributed to the fact that these immigrants encounter more barriers in case of founding a new venture or have more difficulty overcoming the barriers encountered during the process of start up. Often they are not familiar with the necessary start up procedures and there is a lack of trust on the part of other business parties, such as investors and suppliers, who consider the lack of knowledge of the home market, language and customs an important handicap for doing business.

The argument that ethnic minorities are more likely to become entrepreneurs than native people can be related to the margination theory, stating the importance of an (negative) event, triggering the start-up of new firms. According to this theory, the creation of an enterprise is not always the result of a deliberate and intentional act or a result of rational decision making. For most people, starting a business begins with the shattering of a previous life pattern (Veciana, 1999). For individuals or people who are unable to adapt to a social system, such as ethnic and migrant minority groups, their marginal social position is a driving force to become self-employed. Self-employment in this case is not only a means for earning a living, it is also a way of obtaining recognition and social acceptance (Veciana, 1999).

A high immigration rate can be reinforcing because a high number of migrants in a certain area can stimulate migrants to create their own social structure through setting up their own businesses, especially since native

\footnotetext{
${ }^{18}$ This holds especially for countries where immigrants have long had a place in society, like the United Kingdom (Storey, 1994) and the Netherlands (Bais, van der Hoeven and Verhoeven, 1995).
} 
entrepreneurs are less likely to sell foreign products and are often reluctant to set-up a business in areas where immigrants abound (Van den Tillaart and Poutsma, 1998). On the other hand, Clark and Drinkwater (2000) argue that immigrants living in areas with a high percentage of their own ethnic group are less likely to become self-employed as they are separated from native values, norms and way of doing business complicating adjustment and venture creation.

Next to the impact on the number of new ventures, immigration (ethnic entrepreneurship) can exert influence on the exit rate of businesses. As compared to 'native' entrepreneurs ethnic business owners are more likely to start businesses in the service and retail sector, i.e., a sector that is characterized by low entry barriers and high competition and accordingly high failure rates. Moreover, ethnic entrepreneurs often have the tendency to serve their own community with products and/or services from the country of origin which can lead to supersaturation of the sector and excess failure rates (Van den Tillaart and Poutsma, 1998).

\subsection{Participation of women}

In the last few decades the participation rate of women in the labor market has increased substantially in most countries in the Western world (OECD, 2000 and OECD, 1998b). This can be attributed to changing values and attitudes towards working women and the resulting changes in behavior of women. An increase in the participation rate of women does not necessarily imply an increase in the number of female entrepreneurs. It does however increase the likelihood of women to become self-employed. Whether an increasing participation rate of women in the labor market has a positive or negative impact on the number of entrepreneurs depends on the variable against which the participation rate of women is measured. When focusing on the female participation rate relative to the labor force, it can be said that an increase in the participation rate of women has a negative impact on the level of entrepreneurship. This can be explained by the fact that, although the number of women business owners (as a percentage of the population) has been increasing in most Western countries, working women show substantially lower self-employment rates than working men (Bais, Van der Hoeven and Verhoeven, 1995). When focusing however on the participation rate of women relative to the population, it can be said that an increasing female participation rate leads to more (female) entrepreneurs.

Female self-employment rates in developed countries are generally lower than self-employment rates of men (OECD, 1998b). There is however variation between countries with respect to the number of female entrepreneurs that to a large extent can be attributed to differences in institutional and cultural environment. As a consequence it is difficult to make general and unambiguous inferences here.

The lower self-employment rates of women are often attributed to different factors. Evidence is mixed on the difficulties women have with the acquisition of financial capital to start a business (Verheul and Thurik, 2001). It is argued that they either have less financial capital of their own to invest in a business because of discontinuous labor market histories or have difficulties in accessing funds provided by formal financial institutions (OECD, 1998b; Hisrich and Brush, 1987; Riding and Swift, 1990). Other studies, however, argue that female entrepreneurs have equal or even better opportunities to raise financial capital than male entrepreneurs (Buttner and Rosen, 1989; Rosa, Hamilton, Carter and Bums, 1994). An important factor complicating female entrepreneurship is the combination of household and/or family responsibilities, leading to time constraints for women business owners (Loscocco, 1991). On the other hand, women are often attracted to self-employment by the flexible time schedules it offers them (Buttner and Moore, 1997; Brush, 1992).

In addition to their impact on the number of new ventures, women can exert influence on the number of business failures. The impact of female entrepreneurship on failure rates is ambiguous and difficult to assess. Several studies argue that women-owned businesses are characterized by an inferior performance 
and lower survival rates as compared to male-owned businesses (Stigter, 1999; Du Rietz and Henrekson, 2000 and Rosa, Carter and Hamilton, 1996) ${ }^{19}$. This may be attributed to the business sector in which female entrepreneurs engage and/or the time they spend running a business. Women are more inclined to start a business in retailing and services, sectors with relatively low capital investment, more possibilities for parttime entrepreneurship, and a lower expected life span of firms (EIM/ENSR, 1996). Moreover, women often have other activities next to their business, paid or unpaid, leading to time constraints restricting their entrepreneurial activities (Stigter, 1999; Bruce, 1999). Finally, women contribute to the diversity in the supply of entrepreneurship because they have a different approach towards entrepreneurship than men do (Verheul and Thurik, 2001). Female entrepreneurs engage in different sectors and/or activities and have different approaches towards managing the business. Diversity in supplied goods and services leads, through selection by customers, to the survival of high quality businesses. A higher number of female entrepreneurs may result in a decreasing overall business failure rate, even when female-owned businesses have a (slightly) lower survival rate.

\subsection{Income levels and unemployment}

There are conflicting hypotheses that explain the influence of the wage rate on (changes in) the rate of selfemployment. The first argues that if the wage rate is high, the opportunity costs of self-employment are high. The second refers to a high wage rate as an indicator of an affluent economy with above average survival rates of small businesses, resulting in a high rate of self-employment. Lastly, high-income levels, resulting from sustained high wage levels, enable founders to raise start-up capital easily and at low cost.

The same contradictory impact on self-employment is true for unemployment, a variable closely related to the wage rate. When explaining spatial variations in rates of new firm formation, Storey (1994, p. 69) argues that: "...if unemployment is high, then more individuals would be prepared to offer themselves for selfemployment, because of the shortage of alternative job opportunities. On these grounds high rates of, or increases in, unemployment would lead to higher rates of new firm formation. Yet, high rates of unemployment also reflect a lack of buoyancy in the economy, perhaps a lack of 'enterprise' in the population, and therefore a shortage of demand". Unemployment thus appears to have consequences for both the valuation of different types of employment and the number of entrepreneurial opportunities created at the demand side.

At the macro level a high rate of unemployment can negatively impact the level of entrepreneurship through suppressing effects on new ventures, i.e., a decrease in the availability of business opportunities induced by a depressed economy. Moreover, the failure rate of established businesses rises because of low revenues (EIM/ENSR, 1996). On the other hand, at the individual level, (the risk) of unemployment is likely to have a positive effect on the level of entrepreneurship through the reduction of the opportunity costs of selfemployment. When there is little chance of finding paid employment, unemployed people have no other option then becoming self-employed (EIM/ENSR, 1996). Unemployment can be considered a push factor (according to the margination theory) as it turns self-employment into a necessity. Moreover, the duration of unemployment can enhance the need for business ownership. The probability of becoming self-employed increases with the unemployment duration. ${ }^{20}$

There is evidence for a two-way causation of the relationship between unemployment and self-employment. On the one hand a high rate of self-employment can lead to a high growth level of the economy as a whole and to subsequent low levels of unemployment (Audretsch and Thurik, 2000; Carree, Van Stel, Thurik and

\footnotetext{
${ }^{19}$ In a study by Kalleberg and Leicht (1991) it is argued that female-owned businesses are not more likely to go out off business.

${ }^{20}$ In an empirical investigation for 23 OECD countries, Audretsch and Thurik (1998) find a positive effect of the (lagged) change of unemployment on the change of the self-employment rate. They correct for the reversed causality of self-employment influencing unemployment. See also Storey (1991), Evans and Leighton (1990) and Audretsch and Thurik (2000).
} 
Wennekers, 2001) $)^{21}$. A low level of unemployment can stimulate entrepreneurship because it is an indicator of a thriving economy with ample opportunities for entrepreneurship (Audretsch and Thurik, 1998).

\subsection{Income disparity}

In addition to the level of income, income disparity can influence entrepreneurship. Income disparity can impact the level of entrepreneurship through both the supply and the demand side of entrepreneurship. At the supply side high income disparity may push low wage earners and recipients of social security benefits into self-employment, because their opportunity costs of entrepreneurship are relatively low. For poor people starting a business is a necessity (Stanworth and Curran, 1973). A high income disparity may also provide people at the other end of the income distribution with the financial means to cover the risks associated with self-employment and to start a viable business. At the demand side high-income disparity is likely to cause a more differentiated demand for goods and services. People with higher incomes will pursue more expensive (luxury) products in addition to the basic-need-products, whereas people with lower incomes tend to pursue less expensive goods and services ${ }^{22}$. Generally it is assumed that income disparity positively influences selfemployment. Indeed, empirical research by Ilmakunnas, Kanniainen and Lammi (1999), based on a crosssection of approximately 20 OECD-countries, suggests that income inequality positively influences the rate of self-employment. A study of Bosma, Wennekers, De Wit and Zwinkels (2000) also provides evidence in a time series study for the Netherlands.

Moreover, there may be a two-way causation in the relationship between entrepreneurship and the disparity of income. On the one hand, income disparity may stimulate entrepreneurship through both the supply and the demand side. On the other hand, an upsurge of entrepreneurship may be expected to increase the disparity of incomes. The uncertainty of entrepreneurial success is high (many who start a business fail), but there are also considerable chances 'to hit it big'. Inequality will thus be particularly high among the entrepreneurs themselves. OECD (2000, p. 169) provides extensive empirical evidence supporting the argument that the income distribution of the self-employed tends to be less equal than that of wage and salary earners.

\section{$6 \quad$ Individual decision making}

\subsection{Introduction}

So far, we have concentrated on the determinants of entrepreneurship from the perspective of the macro level. Demand and supply factors are also inputs for individual occupational choice. In the present paper it is argued that demand side factors lead to entrepreneurial opportunities and that supply side factors shape the individual characteristics of (potential) entrepreneurs. Resources, ability, personality characteristics and preferences are the main inputs for assessing and weighing the risks and rewards of entrepreneurial opportunities versus those of alternative occupational opportunities. We will not go into a detailed listing of opportunities, resources, abilities, personality traits and preferences. For this information we refer to the extensive literature on (micro-level) determinants of entrepreneurship (Blanchflower and Oswald, 1998; Blanchflower and Meyer, 1994; Evans and Jovanovic, 1989; De Wit, 1993, Van Praag and Van Ophem, 1995; Storey, 1994; Birley and Westhead, 1994; Reynolds, Miller and Maki, 1995). However, the individual

21 Taking into account the two-way causation of the relationship between unemployment and the rate of self-employment there is a clear possibility of a non-linear relationship between unemployment and the number of people starting a business. A positive relationship changes into a negative one, beyond a certain point where potential entrepreneurs are discouraged by the lack of entrepreneurial options and the likelihood of business failure (Meager, 1992). In this sense the positive and the negative effects of unemployment are confined to certain phases of the business cycle. Different countries can have differently shaped relationships between unemployment and the number of (starting) entrepreneurs (Meager, 1992).

22 The impact of income disparity on the demand for entrepreneurship should not be overestimated. The main factor causing differentiation of consumer wants is not income disparity but average per capita income or wealth. 
decision making process and its components will be briefly discussed to illustrate how and when an entrepreneurial decision is made.

\subsection{Opportunities and individual characteristics}

Demand and supply side factors create conditions for the entrepreneurial decision at the individual level. These conditions consist of opportunities, 'external' resources and 'internal' individual characteristics. The latter include ability, personality characteristics and preferences, i.e., values and attitudes. Whether a particular individual acts upon an opportunity depends upon an individual's external resources, ability, personality traits and preferences.

Opportunities $^{23}$ are created by the characteristics of the market. Different types of opportunities can be distinguished. Opportunities for new products arise when customers develop different wants and needs due to increasing income levels or fast technological developments. Increasing or high-income levels lead to a higher variety in the demand for goods and services. It also leads to a higher level of uncertainty since demand becomes more fragmented and whimsical. Both effects lead to more room and opportunities for prospective entrepreneurs. Technological developments enable firms to produce new goods and services and make people aware of the (future) supply of new goods and services, thereby creating a demand for these new products. Moreover, opportunities can arise from possibilities to produce more efficiently, applying a process innovation, or experimenting with new products applying product innovations.

Opportunities for new markets arise when the supply of existing goods and services can be extended to new markets. These markets can either be related to established markets, when the entrepreneur produces goods and services that bear close resemblance (without or with little adjustments) to the initial supplied products or when the market is opened up geographically (to a different town, region or country). New markets also arise as a consequence of an growing tendency towards outsourcing of non-core activities (Carlsson, 1989 and Jovanovic, 1993). Finally, opportunities for entrepreneurial activity depend upon the development of the private service sector vis-à-vis the public provision of services and the evolution of the self-service (household) and the so-called informal or 'gray' sector. Since the late 1980s the balance has shifted towards the private (Wennekers, 1992). These processes are partly driven by new regulation (privatization and deregulation) and partly by a decreasing tax and social security wedge in many countries ${ }^{24}$. Finally, opportunities arise when the number of entrepreneurs is not in line with the optimal or equilibrium number of entrepreneurs. Actual and equilibrium rates of entrepreneurship will be discussed in section 7 .

Whereas opportunities are created at the demand side, the supply side generates (potential) entrepreneurs that can perceive and seize these opportunities provided they have the (external) resources, ability, personality characteristics and preferences to do so.

Resources are necessary means to start a viable business. They include financial capital and other physical means as well as (potential) assistance and information from human contacts (within networks). Financial means either refer to start-up capital in the form of savings, gifts and inheritance, or borrowing capacity based on real estate, reputation or former accomplishments. The relevance of available financial means as a determinant of entrepreneurial activity has been extensively documented (Blanchflower and Oswald, 1998; Evans and Leighton, 1989; Van Praag, 1996). Resources here are considered external to the individual since we distinguish them from 'internal' individual characteristics, such as abilities, personality traits and preferences.

\footnotetext{
${ }^{23}$ Van Praag and Van Ophem (1995) use a broader definition of opportunity, referring to opportunity as "the possibility to become self-employed if one desires this". In their view opportunity is determined by both individual characteristics and the (macro-) economic environment.

${ }^{24}$ Henrekson (2000) presents a model for analysing the impact of taxes and social security contributions on the choice between doit-yourself and purchase on the market.
} 
Following Robbins (1998, p. 46) we define ability as "an individual's capacity to perform the various tasks in a job". Ability here includes both acquired skills and knowledge and aptitude, i.e., an individual's capability of learning, the latter of which is inborn (Robbins, 1998) ${ }^{25}$. For an entrepreneurial opportunity to materialize it is important that an individual has the ability to perceive the opportunity and possesses the knowledge and skills needed to act upon this perception. Adequate 'entrepreneurial' skills and knowledge, such as managerial skills and knowledge of marketing and human resource management, can be developed through labor market experience or the start-up or management of a previous business. In addition, an individual needs to be able to adequately assess future rewards and risks of the perceived opportunity. Because an entrepreneur is often exposed to uncertainty when dealing with changing market conditions, the capacity to learn from mistakes or new experiences is important for the survival of the business.

The extent to which individuals are fit to become self-employed also depends upon their personality characteristics. Personality traits often associated with entrepreneurial success are creativity, initiative, opportunity seeking, internal locus of control and persistence (Van der Kuip, 1998). Entrepreneurial personality characteristics are partly inborn but can also be enhanced through previous self-employment and other relevant experience (Evans and Leighton, 1989; Van Praag, 1996), and can possibly be developed through education and training, albeit in an early phase (Van der Kuip, 1998).

Whereas resources, ability and, to a lesser extent, personality characteristics pertain to the possibility of an individual to take up a certain profession, preferences refer to the desire or willingness ${ }^{26}$ of an individual to choose one profession over the other. In order for individuals to act upon an entrepreneurial opportunity it is a necessary (but not a sufficient) condition that they have a positive attitude towards, and place a value on, entrepreneurship. Personal preferences relate to the degree of openness of an individual to self-employment and include financial and immaterial goals, such as the valuation of autonomy. It also embraces the attitude towards risks.

\subsection{Risk-reward profile}

In modeling occupational choice and particularly the choice between business ownership and wage employment it is often assumed that individuals compare the expected financial and non-pecuniary rewards of these alternatives ${ }^{27}$. However, it can be argued that individuals not only compare the rewards but also the risks of occupational alternatives: the net rewards of occupational alternatives can be calculated ${ }^{28}$.

In the present paper occupational choice is defined as the process of weighing the risks and rewards of different types of employment taking into account both environmental factors (opportunities) and individual characteristics (resources, ability, personality and preferences).

The risk-reward profile of self-employment versus other types of employment encompasses the valuation of expected relative rewards and risks. The better the prospects of entrepreneurial income as compared to the income out of wage-employment or unemployment benefits, the more people will seriously consider the option of entrepreneurship. However, average income is not the only factor involved in the decision. Even when the average entrepreneurial income is high as compared to the average income out of wage employment (or unemployment), its dispersion is high and the success of a business is highly uncertain in the start-up phase (Parker, 1996; Bosma, Zwinkels and Carree, 1999). Moreover, when choosing to become self-

\footnotetext{
${ }^{25}$ Other research in this area does not subsume aptitude under ability but refers to aptitudes as potential abilities and abilities as the knowledge and skills an individual currently possesses (Schermerhorn, Hunt and Osborn, 2000, Wagner and Hollenbeck, 1995). For the purposes of the present paper we choose however to include aptitude with ability.

${ }^{26}$ Van Praag (1996).

27 See Acemoglu (1995) and Murphy et al. (1991). An earlier model distinguishing between entrepreneurship and wageemployment, couched in terms of opportunity costs of entrepreneurship, is presented by Lucas (1978).

${ }^{28}$ The net rewards of occupational alternatives are calculated correcting the rewards for inputs, like working hours, and other costs. Unemployment and unpaid (family) work are included with the occupational alternatives.
} 
employed, the possible consequences of failure may include the loss of entitlements to social security, in addition to the stress caused by the loss in income. When entrepreneurship entails the loss of health care coverage, pensions and invalidity insurance, the opportunity costs of self-employment increase, enhancing the preference for salaried employment ${ }^{29}$. The (relative) absence of these benefits for self-employed people can be relevant particularly in the early phase of the business (OECD, 1998a) and is likely to discourage potential entrepreneurs from leaving secure jobs.

An individual thus decides upon an entrepreneurial opportunity by comparing the subjective returns of becoming an entrepreneur with the subjective returns of performing an alternative income-producing activity (Minniti and Bygrave, 1999). Expected returns can both be financial, i.e., wages and profits, and nonpecuniary, i.e., working hours ${ }^{30}$, and are weighted against the risks of failure or dismissal. These risks refer to both financial liabilities and the stigma attached to failure. Total utility of each occupational alternative depends upon personal assessments of all financial and non-pecuniary risks and rewards. Weighing the alternatives according to personal preferences results in an individual's risk-reward profile of self-employment versus wage-employment ${ }^{31}$ (or unemployment).

To create more insight into the relationship between demand and supply side factors at the macro level and the individual risk-reward profile of self-employment versus other types of employment, below we will discuss the impact of dissatisfaction and the interest rate on the individual decision making process, respectively. Clearly, the impact of dissatisfaction could be discussed also in the section on unemployment or immigration, whereas that of the interest rate could be discussed in the section on input-related policies.

Dissatisfaction with the current (un)employment situation positively influences the risk-reward profile of entrepreneurship and company formation (Shapero and Sokol, 1982; Brockhaus, 1980a, 1980b and 1982). Brockhaus states that dissatisfaction with the previous work situation is closely related to the entrepreneurial decision. He finds that self-employed people are relatively dissatisfied with the previous work itself, supervision and the opportunities for promotion ${ }^{32}$. Not only can dissatisfaction with the work situation influence the risk-reward profile, but also other negative social events or shifts, such as forceful emigration or boredom and anger in a more general sense, i.e., 'negative displacements', can stimulate people to become an entrepreneur (Shapero and Sokol, 1982). Most studies concerning the impact of dissatisfaction on selfemployment use individual micro data. Noorderhaven, Wennekers, Hofstede, Thurik and Wildeman (1999) however found that dissatisfaction is also an important factor at the national level. Across countries, dissatisfaction with life and society positively influence the number of self-employed. The more people are dissatisfied with their life and/or with the society they live in, the higher the proportion of self-employed people in the labor force.

A high interest rate is expected to exert a negative influence on the risk-reward profile of entrepreneurship in several ways. A high interest rate implies high opportunity costs of self-employment because of foregone alternative investment opportunities. Moreover, personal financial resources often do not suffice for a business start-up, which forces potential entrepreneurs to make use of other sources of capital, such as debt capital. The interest rate on bank loans and other debt capital presents costs and risks that will have to be taken into account when deciding whether to become self-employed or not. Debt financing with high interest rates increases the financial risk of the firm because of the risks of liability and redemption and the fact that

\footnotetext{
${ }^{29}$ Whether an individual considers these risks important factors in the decision to become self-employed depends on the risk propensity of an individual (Brockhaus, 1980b). Individuals with a high propensity to take risks may be more likely to become an entrepreneur as rewards of entrepreneurship are considered more important than the risks involved.

30 OECD (2000, p. 170) summarizes considerable evidence that on average self-employed people work longer hours than employees. At the same time there is evidence that, in spite of longer hours and poorer working conditions, the self-employed have a higher work satisfaction than employees (OECD, 2000, p. 171).

${ }^{31}$ An alternative formulation would be to consider the expected rewards of wage-employment as the opportunity costs of selfemployment.

${ }^{32}$ With respect to their actual financial compensation the self-employed were less dissatisfied.
} 
interest payments on debt are paid when due, irrespective of the firm's profitability and/or liquidity levels. Hence, a high interest rate is likely to discourage potential entrepreneurs from starting up a business, because of the (high) costs and risks involved. Next to the level of the interest rate, interest fluctuations could also imply risks for the start-up of a new venture with debt capital.

\section{$7 \quad$ Actual and equilibrium rates}

\subsection{Actual and equilibrium rates}

As presented in the previous section, changes in the rate of business ownership are determined by the entry and exit of entrepreneurs making occupational choices on the basis of their risk-reward profiles. People can either be pushed into entrepreneurship in case of an unfavorable risk-reward profile of wage employment or unemployment or pulled towards entrepreneurship in case of a favorable risk-reward profile of selfemployment. Moreover, incumbent entrepreneurs can decide to voluntarily close down their business because of high opportunity costs, i.e., better alternatives. However, not all closures are voluntary and some entrepreneurs are forced to close their business because it is no longer viable. At a more aggregate level it can be said that the actual level of entrepreneurship is determined by a combination of the many factors at the demand and supply side of entrepreneurship: opportunities, resources, abilities and preferences determine the landscape of risk-reward profiles of entrepreneurship versus wage-employment at the individual level.

Next to the actual level of entrepreneurship in a certain country and a certain period there is the concept of an equilibrium rate of entrepreneurship. This equilibrium rate can be considered a long-term equilibrium depending upon the stage of economic development in a country. The actual level of entrepreneurship does not necessarily equal the equilibrium level. There are different views on the factors determining the equilibrium rate of entrepreneurship (Lucas, 1978; De Wit and Van Winden, 1991). Carree, Van Stel, Thurik and Wennekers (2001) present theoretical and empirical evidence of a long-term relationship between the stage of economic development and the equilibrium level of business ownership. There is also some evidence that this relationship is U-shaped. Carree et al. (2001) mention a Schumpetarian regime switch as the cause of the recent reversal ${ }^{33}$ of the prolonged downward trend in the equilibrium rate of entrepreneurship. Piore and Sabel (1984) use the term Industrial Divide and Jensen (1993) uses the term Third Industrial Revolution. Audretsch and Thurik (2001) make a distinction between the managed economy and the entrepreneurial economy. The study by Carree et al. (2001) also shows that countries where the rate of business ownership does not equal the equilibrium rate suffer from a lower rate of macro-economic growth. In this respect the equilibrium level can also be interpreted as an 'optimal' level. Finally, it is shown that both market forces and government intervention can restore the equilibrium.

\subsection{Restoring equilibrium}

Many forces may cause the actual number of entrepreneurs to differ from the long-term equilibrium rate (Carree, Van Stel, Thurik and Wennekers, 2001). This 'disequilibrium' may stem from cultural forces and institutional settings, such as the regulation of entry, incentive structures and the functioning of the capital market (Davis and Henrekson, 1999 and Henrekson and Johansson, 1999). Market forces and policy measures play a role in restoring the equilibrium. Different perspectives exist on the role of the government in the economic process. There are theories, e.g., Austrian School, Chicago School, that regard government intervention in the national economy as harmful and disturbing, whereas 'antitrust' schools of thought argue

\footnotetext{
${ }^{33}$ The proportion of the labor force that is self-employed has decreased in most Western countries until between the mid-1970s and the mid-1980s. Since then the self-employment rate has started to rise again in several of these economies. Also see Table 1 of the present paper.
} 
that the government has an important role in giving direction to the economic process, i.e., addressing market failure. Implicit in the different strands of thought is the argument that government intervention is responsible for either corroding or restoring equilibrium.

In arguing that the actual and 'optimal' level of entrepreneurship do not necessarily coincide and that the government can react to this unbalance, the present study attributes a (potentially) positive role to government intervention. In the framework of Figure 1 five avenues of policy measures are distinguished. Depending on the nature of the (assumed) disequilibrium, the government can try to restore equilibrium through policies fostering or restricting entrepreneurship. In order to intervene properly in the national economy, it is important that the government is able to perceive a deviation from the equilibrium rate of entrepreneurship. When the government is mistaken or has its own specific political ideas about the 'optimal' level of entrepreneurship, government intervention is likely to have a 'disturbing' rather than a 'restoring' effect. In this sense the government can also be a source of disequilibrium.

However, market forces can also play a role in restoring the equilibrium. In particular, this restoring capacity of the market works through (the valuation of) the number and type of entrepreneurial opportunities. In the late 1970 s and the early 1980 s the structurally low number of enterprises is likely to have contributed to a high level of unemployment (Carree, Van Stel, Thurik and Wennekers, 2001). A high level of unemployment can push people into self-employment due to the relatively low opportunity costs of entrepreneurship (Storey, 1991; Evans and Leighton, 1989a; Audretsch and Thurik, 1998) ${ }^{34}$. Moreover, when the number of business owners exceeds the 'optimal' rate this is assumed to diminishing profitability, due to higher competition, resulting in high exit or failure rates and lower entry.

\section{Government intervention}

\subsection{Introduction}

In the previous sections it has been made clear that market forces on both the demand and supply side impact the level of entrepreneurial activity. Moreover, the government will be inclined to influence the actual level in the case of perceived deviations from the equilibrium ('optimal') rate of entrepreneurship. The government can fulfil different roles in the economic environment. First, it creates a legal framework in which the property rights of all market parties are guaranteed and protected. This general role of the government is supplemented with a 'correcting' role of the government in case of market failure. Market failure can take different forms, such as market concentration undermining competition; information discrepancy between market parties; absent or dysfunctional markets; externalities and collective goods. The 'correcting' role of the government is aimed at free competition, leading to efficient allocation of scarce resources. Also, the government sees to it that market parties act in accordance with what is considered 'fair'. An example is government intervention in the distribution of income. Finally, the government also acts as a market party through government expenditures.

These general roles of the government can also be applied to entrepreneurship. Government intervention within the field of entrepreneurship is inspired by the importance of the small business sector for economic growth and job creation. In their first life phase small businesses are often weak and in need of some support and protection to be able to properly compete in the market place (at a later stage). An additional task of the government may be to warrant the quality of entrepreneurship; too many small businesses may erode the quality of supplied goods and services. The government may try to promote quality through the implementation of different laws and regulations, such as the establishment legislation, measures enhancing

\footnotetext{
${ }^{34}$ It has to be born in mind that at the aggregate level (high) unemployment may also correlate with recession and declining entrepreneurial opportunities.
} 
competition, i.e., preventing market concentration, and environmental laws. Next to sustaining quality, government regulation enables entrepreneurs to run or start a business providing minimal and transparent procedures and arbitration ${ }^{35}$. Also, the government can reduce market failure in the field of entrepreneurship by removing barriers to entry. Barriers to entry not only result from concentration in the market, but may also result from incomplete information or shortage of finance.

In the present paper it is argued that the government is able to influence the rate of entrepreneurship through the five different groups of determinants of entrepreneurship as represented in Figure 1. For this purpose a distinction is made between five types of policy measures:

G1. Government intervention on the demand side of entrepreneurship; influencing the number and type of entrepreneurial opportunities.

G2. Government intervention on the supply side of entrepreneurship; influencing the number and type of potential entrepreneurs.

G3. Government policies aimed at influencing the availability of resources, skills and knowledge of individuals. These policies generally deal with the input factors of entrepreneurship, i.e., labor, finance and information.

G4. Government policies aimed at influencing the preferences, i.e., values and attitudes, of individuals.

G5. Government policies (directly) aimed at the decision-making process of individuals. Given certain opportunities and individual characteristics, this type of government intervention directly influences the risk-reward profile of entrepreneurship.

Before going more deeply into the above classification of government intervention, section 8.2 presents an overview of the field of government policy and entrepreneurship according to some more traditional perspectives. This is done to create insight into the relationship between government intervention and entrepreneurship from a traditional point of view. Subsequently, in section 8.3 the five different types of government policy distinguished in this paper will be related to the traditional perspectives to investigate whether there are differences or whether there is overlap.

\subsection{Government policy and small business: some traditional perspectives}

Government policies with respect to small business and/or entrepreneurship can be categorized according to different perspectives and views. In a study on SME government policies in the United Kingdom Storey (1994) distinguishes between macro policies, such as interest rates and taxation; deregulation and simplification; sectoral and problem-specific policies; financial assistance and indirect assistance, i.e., informational services; and the relationship between small firms and the government. Another type of classification is according to input and output or enabling and constraining measures (Audretsch and Thurik, 2000 and 2001). Government policies can be directed either at the input side of entrepreneurship, i.e., labor, finance and information, or the output side of entrepreneurship, i.e., opportunities for sales. Next to these input- and output-related policies the government can create conditions of entrepreneurial activity or combat its detrimental effects. Moreover, policies can either be generic, i.e., aimed at the whole economy, or specific, targeted at entrepreneurship. In KPMG/ENSR (2000, chapter 8) eight fields of planned and implemented actions are distinguished when dealing with recent policy developments in SME-specific fields (administrative burdens; late payment; finance; internationalization; information; labor training; R\&D and innovation; fostering

\footnotetext{
${ }^{35}$ Next to the range of laws and regulations, the quality of legislation is important; the energy, time and money spent on the compliance with government regulation need to be minimized in order for the entrepreneur to have maximum resources
} available to spend on the basic activities. 
entrepreneurship). ${ }^{36}$ Next to solely consisting of policy measures and government regulation, intervention can be interpreted in a broader way, including education and culture.

In the remainder of section 8.2 the impact of government policy on entrepreneurship is dealt with according to a classification based on the above-mentioned perspectives.

\subsubsection{Macro-economic policies}

\section{Introduction}

Macro economic policies are generic; they concern the economy as a whole and are not directly aimed at influencing the level of business ownership. These policies often have an important impact on the trading position of small firms (Storey, 1994). Macro economic policies provide a framework within which businesses of all sizes practice their activities. Examples of macro economic policies that have impact on entrepreneurial activity are taxation, labor market regulation, social security and income policy. The impact of these policies on entrepreneurship will be dealt with in the subsequent sections.

\section{Taxation}

Governments exert influence on the relative net earnings of different types of employment through the tax system. The impact of taxes on the level of entrepreneurship is complex and even paradoxical. In OECD (1998a) it is argued that high tax rates reduce the returns on entrepreneurship and can impede the start-up of new firms and expansion of established firms. Tax payments are at the expense of retained earnings and negatively affect the liquidity position of businesses. Moreover, high growth businesses, i.e., 'gazelles', are penalized by high marginal income- and corporate tax rates. As a consequence, high tax rates induce tax avoidance and evasion, for example through moonlighting, thereby reducing the opportunities for legitimate entrepreneurship. On the other hand, it has been hypothesized that self-employment offers better opportunities to evade or avoid tax liabilities than wage-employment (Parker, 1996, p. 466). In the latter case higher (marginal) tax rates could promote self-employment. ${ }^{37}$

In addition to the general impact of taxes, the impact of different types of taxation on entrepreneurship needs to be addressed. For example, the taxation of dividends may result in the reliance on retained earnings when financing expansion. This inhibits a flow of capital in the most promising projects. Moreover, capital tax on new equity can discourage equity financing and high payroll taxes make it difficult for entrepreneurs to hire labor at a price that corresponds with the value of the employee to the entrepreneur.

Additionally, Davis and Henrekson (1999) contend that the tax system can introduce distortions. For example: tax exemption rules in Sweden, favoring capital-intensive manufacturing industries, have tilted the size distribution away from high potential enterprises towards large firms. They also conclude that in Sweden effective tax rates for family businesses are much higher than for other firms.

\section{Labor market regulation}

Generic legislation can also be directed towards the risks involved in different kinds of employment. An important risk (potential) small business owners have to face is insufficient or inadequate availability of personnel. Often small businesses have relatively more difficulty hiring adequately skilled personnel than large businesses. Large businesses often offer better (vertical) promotion opportunities and higher salaries

\footnotetext{
${ }^{36}$ In KPMG/ENSR (2000) an account is also given of the national policies of 19 European countries as well as what is considered best practice.

${ }^{37}$ An investigation by Parker (1996), using data from the United Kingdom, supports this hypothesis. More, and partly contradictory, evidence concerning the effects of average and marginal tax rates on self-employment is presented in OECD (2000, p. 173).
} 
for the same activities (Brown, Hamilton and Medoff, 1990). Against this background employment flexibility is important for small businesses. Heavy unionization in a country, resulting in a strong regulation of 'hire and fire' increases the risks of business-ownership because of the difficulty for business owners to adjust their workforce in correspondence with market fluctuations. At the same time the risks for employees are relatively low in such an environment. Labor market regulation thus can constrain new entrepreneurial activities (OECD, 1998a). In recent years the deregulation of labor markets has made wage-employment more insecure and stimulated entrepreneurial activity in many countries (OECD, 2000).

\section{Social security}

The possible loss of entitlements to social security when becoming self-employed can constrain entrepreneurial activity ${ }^{38}$. When entrepreneurship means giving up benefits, such as health care coverage, retirement pensions, disability or unemployment insurance, the opportunity costs of self-employment increase, thereby enhancing the preference for salaried employment. Moreover, a high level of social benefits is likely to discourage unemployed people to start a business to escape from unemployment (Bosch and Westhof, 1997). In addition to the absolute level of social security the difference in safety nets between wage earners/unemployed people and business owners influences the level of entrepreneurship ${ }^{39}$. The absence or inadequacy of safety nets for the entrepreneur can be particularly relevant in the early phase of the business (OECD, 1998a).

Social security systems can be divided in three types of schemes (Baenen and Visser, 1996): universal schemes, general schemes and categorical schemes. Under a universal scheme (basic) social protection is organized in the same scheme for all professional groups. This means that self-employed and wageemployed people are equally insured and by the same laws. In this case there is no (dis)-incentive within the social security system for people to become self-employed. The general scheme refers to equal treatment of all self-employed people; self-employed are insured within the same scheme, whereas employees are insured within a different scheme. When the insurance provided to employees and employers differs to a great extent, there are (dis)-incentives to become an entrepreneur. Within the categorical schemes a distinction is made between professional groups of self-employed. In this case starting or running a business could be more attractive with respect to insurance in one sector than in another. The type of social security schemes implemented differs considerably between countries.

\section{Income policy and income disparity}

Governments can directly impact the risk-reward profile of entrepreneurship versus other types of employment through exerting influence on wages and the relative gross returns of business ownership. For example, a policy of wage moderation can stimulate entrepreneurship through lowering the costs of hiring labor. Indeed, research by Carree, Van Stel, Thurik and Wennekers (2001) suggests that the labor income share in the national income has a negative influence on the business ownership rate in 23 OECD countries. This finding is supported by a study of Bosma, Wennekers and Zwinkels (2000) showing that sustained wage moderation in the Netherlands has contributed to the revival of self-employment.

Income policy, in particular when affecting the income distribution, may also create some (indirect) incentives for self-employment, since income disparity can influence the level of entrepreneurship both through the demand and the supply side.

\footnotetext{
${ }^{38}$ Social security here is defined in a broad manner, including other benefits, in addition to retirement pensions.

${ }^{39}$ In the United States self-employed individuals are required to pay into social security via self-employment taxes. This rate is two times higher, since it includes both the shares of employers and employees.
} 


\subsubsection{Regulation of dynamism}

\section{Introduction}

The level of entrepreneurship is determined by the balance of entry and exit of firms. The sum of entry and exit, i.e., business turbulence, may be an important driving force for productivity growth and innovation (Bosma and Nieuwenhuijsen, 2000). To guard the number and quality of entrepreneurial ventures, governments sometimes try to regulate entry and exit flows of entrepreneurship through special legislation. Two examples of this type of legislation, namely business licensing (establishment legislation) and bankruptcy legislation, are dealt with in the following sections.

\section{Establishment legislation}

In most countries several legal demands have to be met when starting a business. Often, as is the case in the Netherlands, a potential entrepreneur is required to have certain skills or know-how, depending upon the sector $^{40}$. Establishment requirements can be general, applying to all small businesses, or more specific, applying to a certain industry or occupation. General skill requirements may relate to different aspects of selfemployment, such as management, finance and marketing, while specific skill requirements relate to industry- or occupation specific aspects of e.g., health-related professions, technical professions or the hotel and catering industry. In addition to skill requirements business owners need to comply with environmental and safety legislation and have to take into account registration procedures, including those concerning social security and taxes.

The impact of establishment legislation on the level of entrepreneurship is ambiguous. On the one hand, establishment legislation can be a serious barrier for (potential) entrepreneurs as it raises the costs of starting or running a business. These costs can take different forms. A distinction can be made between the amount of money necessary to comply with the establishment legislation, the length of time necessary to complete the legislation procedures and the complexity of the procedures in the establishment process. These costs might lead potential entrepreneurs to shy away from risk-taking (OECD, 1998a). On the other hand, it is conceivable that establishment requirements contribute to a higher quality of entrepreneurship and a higher survival rate, thus having a positive impact on the level of entrepreneurship in the long run. However, the evidence in this direction is scarce. ${ }^{41}$

\section{Bankruptcy policy}

Firm closure is part of the entrepreneurial process and allows resources to move to their most productive uses. Policies that restrict the scope for firms to restructure or close diminish the ability of an economy to adjust and discourage entrepreneurs from starting up (OECD, 1998a). At the individual level potential entrepreneurs can be discouraged by severe bankruptcy regulation if, in their assessment, the possible penalties for going bankrupt offset the potential rewards of starting a business.

The government has several means to relieve the costs in case of (personal) bankruptcy. Discharge clauses free the debtor of his debt within a certain time span. The extent to which discharge clauses are in use varies between countries. In the Netherlands entrepreneurs that go bankrupt are required to settle their debts, if possible from future earnings. This places a constraint on prospective entrepreneurial activity (OECD,

${ }^{40}$ In the Netherlands a relaxation of skill requirements has recently been implemented. The general skill requirements will be abolished by the $1^{\text {st }}$ of January 2001, whereas the complete establishment act, including industry-specific and occupationspecific requirements, is to be withdrawn by 2006. In this way, the Dutch government tries to improve the entrepreneurial climate $(E Z, 1999)$.

${ }^{41}$ The relaxation of establishment requirements in the Netherlands was shown to have a positive impact on the number of start-ups (Bosma, Zwinkels and Carree, 1999), without negatively influencing the 'quality' of entrepreneurship. See also Carree and Nijkamp (2001) for the influence of deregulation in the retail sector on the speed of entry and exit. 
1998a). In contrast, in the United States owners of failed businesses are not required to pay off their debts, with the exception of their pay roll taxes, i.e. contribution for social security and unemployment benefits. Next to discharge clauses other rescue possibilities, such as the postponement of debts and restructuring, are available to businesses in distress. A postponement of debt, i.e., temporary debt moratorium, is frequently used, whereas reorganization is more infrequent (EIM/ENSR, 1997). During the time of reorganization debts are frozen or need not fully be repaid.

Furthermore, bankruptcy policies vary according to the balance between competing stakeholders groups and the degree of government intervention. Bankruptcy policy needs to strike a balance between creditors' and the enterprise's needs. A legal framework enabling (temporary) postponement of commercial debts protects enterprises in distress, and at the same time (albeit indirectly) encourages late payments, thereby damaging the position of the creditors (EIM/ENSR, 1997).

Bankruptcy can also have a non-financial consequence, namely stigma. Social attitudes towards bankruptcy differ between countries. In the United States failure is often seen as an unfortunate outcome of a 'good try', whereas in most European countries bankruptcy is considered a personal failure (OECD, 1998a). For stimulating start-ups it is important that governments take action to positively influence the public attitude towards business failure. ${ }^{42}$

\subsubsection{Deregulation and simplification}

\section{Introduction}

According to Storey (1994) deregulation consists of two elements. The first is related to stimulating free markets and increasing the opportunities for competition. The second refers to lifting administrative and legislative burdens that take time, energy and resources away from fundamental entrepreneurial activity.

\section{Deregulation and competition policy}

The impact of deregulation and competition policy on the number of entrepreneurs can be divided into effects at the entry- and the exit-side of entrepreneurship. Relaxation of entry regulations stimulates the number of start-ups, as was shown in the previous section. Next to new business formation, industry deregulation and increased competition can have other benefits, such as lower prices, higher productivity growth, new products and new jobs ${ }^{43}$. Increased competition can also impact the failure rate, i.e., exit, of new and established businesses. Policies to promote competition not only include the removal of rules that restrict competition. It also involves the introduction of (new) rules and institutional arrangements in dysfunctional markets, i.e., markets where the absence of rules and regulations harm the functioning of the market (Dutz, Ordover and Willig, 2000).

Deregulation is closely related, and often accompanies, privatization. The aim of privatization is to improve efficiency through restructuring firms and reallocating control rights over employment from politicians and civil servants to commercial managers. It leads to the disintegration of the public enterprise into separate entities. In many cases privatization goes hand in hand with the rapid introduction of a competitive market to prevent monopoly situations (Carree, 1997).

The aim of deregulation is to remove regulative barriers, such as business licensing, while competition policy focuses on the elimination of market barriers to entrepreneurship, such as cartel agreements. Established firms can collude in many ways to prevent new firms from entering the market, for example by denying them

\footnotetext{
42 The degree of intervention of the government in the bankruptcy procedure varies across countries (EIM/ENSR, 1997 and De Koning, 1998).

${ }^{43}$ For some empirical evidence see Lever (1997) and Lever and Nieuwenhuijsen (1999).
} 
access to raw materials and distribution channels ${ }^{44}$. It can be said that entrepreneurship and competition are interrelated since competitive entry often involves entrepreneurial activity and (potential) competition often requires opportunities for entrepreneurship (Dutz, Ordover and Willig, 2000) ${ }^{45}$.

\section{Administrative burdens and the compliance costs of legislation}

Too much and unclear legislation can discourage entrepreneurial activity (OECD, 1998a). Small businesses are relatively sensitive to the administrative costs of the compliance with government regulation, as compared to larger businesses. The time and energy entrepreneurs spend on administrative commitments distract them from their basic (entrepreneurial) activities (EZ, 1999). Not only are administrative burdens a barrier to entry, they are also a barrier to firm growth (Nijsen, 2000). Entrepreneurs can be discouraged from hiring employees because of the administrative procedures involved (Niehof, 1999). Administrative costs also occur when administrative procedures are opaque. Often government institutions use different concepts to discuss similar subjects obscuring government regulation and assistance. The tax system is a good example. It often confuses entrepreneurs due to ambiguously written rules, frequent changes, expiration clauses and different layers of taxation (regional and national). Moreover, the 'language of tax' is usually difficult to comprehend ${ }^{46}$.

\subsubsection{Input-related policies}

\section{Introduction}

Government policies that are input-related stimulate resources available to small firms: labor, financial capital and information/knowledge ${ }^{47}$. A distinction can be made between assistance policies aimed at improving the financial conditions of businesses and those that are designed to improve the efficiency of the firm (Storey, 1994). Financial assistance aims at reducing market imperfections; i.e., the finance gap ${ }^{48}$, and can take the form of development of alternative capital markets, such as the venture capital market, or the direct payment of grants, loans or subsidies to the firm. By contrast, efficiency-enhancing policies stem from the need to overcome information imperfections and often include business training and the provision of information, through consultancy and counseling.

\section{Functioning of the venture capital market}

New and established businesses often have difficulties with the acquisition of capital (Gaston, 1989 and Gompers, 1999). Most starting entrepreneurs obtain financial resources from family and friends. However often additional financial resources are required to finance the start-up or expansion of the business (Gaston, 1989 and Gompers, 1999). These additional financial resources can be acquired through formal and informal financial institutions. However, because of the high risks involved and often the lack of a track record, most financial institutions are reluctant to lend money to early-stage and seed businesses. Moreover, the majority of these businesses often are too small to raise equity on public exchanges to finance start-ups and/or (early)

\footnotetext{
${ }^{44}$ Most countries have adopted competition laws, prohibiting this kind of anti-competitive behavior. Sanctions vary from fines to imprisonment (OECD, 1998a).

${ }^{45}$ There is however a strand of literature suggesting that competitive forces are harmful for entrepreneurship (Dutz, Ordover and Willig, 2000). (Schumpetarian) arguments favoring a negative impact of competition on entrepreneurship, are: competition erodes profits that are necessary for internal funding of entrepreneurial activity and the small size of businesses is a bottleneck to innovative entrepreneurship, since economies of scale (and scope) are necessary to extract the benefits accruing from successful entrepreneurial activity.

${ }^{46}$ Information technology (electronic filling) could be used to reduce the administrative or compliance burden of the tax system. In several countries governments have taken action to streamline administrative requirements and improve the coordination between public agencies (OECD, 1998a).

${ }^{47}$ Labor market policies have been dealt with in the section on macro economic policies.

48 The 'finance gap' is attributed to the risk adversity of banks, choosing to ration credit, because of imperfect information. Small and new (innovative) firms are particularly vulnerable to this credit rationing, since they are more likely to fail and are thus considered more risky (OECD, 1998a).
} 
growth. Thus venture capital can be used as an alternative to 'regular' financial resources (Borger et al., 2000).

As defined by Sofrova venture capital is capital provided by firms, full-time professionals or private persons who invest alongside management in young, rapidly growing or changing privately-owned companies which have the potential to develop into significant businesses (Sofrova, 1996). Venture capital is particularly important for financing high-risk, high-return projects and is often issued to young firms, typically those developing innovative technologies (OECD, 1998a). A distinction can be made between formal and informal venture investors. Formal venture capital refers to investments made by corporate investors, government bodies, banks, pension funds and/or insurance companies (financial institutions), while informal venture capital consists of investments by private individuals Moreover, investors can either have an active or passive involvement in management of the business (Sofrova, 1996).

A well-developed venture capital market is assumed to stimulate high risk, high profit start-ups. Moreover, bankruptcy due to 'undercapitalization' can be prevented by providing the necessary financial resources to small firms. A well-developed venture capital market is thus likely to have a positive impact on entrepreneurship. Nonetheless, the degree to which the venture capital market is developed varies between countries. Three types of venture capital markets can be distinguished to characterize the (venture) capital market of a country: the bank-oriented system; the Latin system and the market-oriented system. ${ }^{49}$

Possible explanations of underdevelopment of the venture capital market are restrictions on the institutional investors' holding of unlisted equity and the difficulty of exit for venture capital. Moreover, according to Borger et al. (2000) a distinction can be made between different cultural characteristics that are assumed to impact the attitudes of investors and entrepreneurs, such as attitude towards risk and loss of control. These cultural characteristics can indirectly influence the development of the venture capital market. Risk adversity is likely to negatively influence the development of the venture capital market, because the supply of venture capital often involves high risk. Moreover, making use of venture capital is often accompanied by a loss of control. As compared to the venture capital market in the United States the European venture capital markets are characterized by the reluctance of European entrepreneurs to accept the loss of control that constitutes venture funding and the variation in rules applying to public listing in different European countries (OECD, 1998a).

The government can support the development of the venture capital market by intervening in both the supply and the demand of the venture capital market. These measures can be divided in direct and indirect measures (Borger et al., 2000). Indirect measures include stimulation of the secondary market and encouragement of financial institutions to offer a wide range of products. Direct measures include a direct supply of capital to the small business sector and financial incentives to invest in (new) ventures.

\section{Specific entrepreneurship support policies}

Governments in developed economies have devised many different policies to support small businesses (KPMG/ENSR, 2000, chapter 8) This assistance usually takes the form of direct financial payments and free or subsidized advisory services. A number of these support schemes are specifically directed at supporting the start-up of new enterprises.

\footnotetext{
${ }^{49}$ The bank-oriented system is characterized by underdevelopment of the stock exchange market and the important role of banks as providers of (venture) capital. There is a concentration of shares with a limited group of shareholders. The Latin system is also characterized by underdevelopment of the stock exchange market. Relatively many businesses and financial holdings are family-owned or state-owned. The market-oriented system is characterized by the separation of property and management. There are many shareholders and banks have a limited role in the provision of (venture) capital. The stock exchange market is well developed and there are many different suppliers of risk capital.
} 
First, there are credit facilities for starting enterprises within the framework of an SME guarantee scheme. It is assumed that credit is rationed because lenders have incomplete information about the projects proposed by borrowers (Cressy, 1996). This credit rationing may hit small entrepreneurial firms particularly hard, since they are perceived to be a riskier investment and often do not have collateral to cover loans. The government can introduce loan guarantee schemes to solve this problem. Evidence for the impact of these schemes on the development of small businesses is mixed (OECD, 1998a). An important problem facing guarantee schemes is the inefficient allocation of resources. Most loans are distributed to firms that already have access to sources of 'regular' financial institutions (OECD, 1998a).

Other types of support for (new) small businesses are fiscal facilities, such as tax exemptions, that are sometimes available for start-ups and young enterprises, and subsidized facilities, such as courses, information and advice. Finally, networks of entrepreneurs can stimulate the exchange of information between entrepreneurs and (subsidized) mentors, i.e., senior/successful entrepreneurs, can support new entrepreneurs.

However, as Storey (1999) has pointed out, adequate evaluations of these different support schemes are rare and it is often unknown to what extent these policies meet their objectives. Storey (1999) argues that the effectiveness of support schemes should be both monitored and evaluated. Monitoring includes specification of the characteristics of individuals taking up the scheme, probing recipients' opinions and their views on the extent to which the scheme made a difference. Evaluation ideally involves the comparison of assisted businesses with non-assisted businesses with the same characteristics, such as age and sector, and taking account the 'selection bias', i.e., businesses that seek assistance are likely to differ from businesses that do not. According to Storey (1999) the government needs to pay attention to all components before bringing about 'heaven', i.e., government support that is efficient and effective.

\subsubsection{Sectoral and problem-specific policies}

\section{Introduction}

Next to general policies, focusing on the (small) business sector at large, policies can be distinguished that focus on specific sectors, regions or groups. In many countries specific policies exist for stimulating entrepreneurial activity among different groups of people, such as women, young people, immigrants and unemployed people, and within specific sectors of industry, such as the IT-sector. Moreover, specific policies focus on stimulating entrepreneurial activity in specific rural or urban areas, and in businesses with certain characteristics, such as high-tech and fast-growing businesses.

\section{Stimulating entrepreneurial activity among groups of people}

Although young people often indicate a preference for self-employment (OECD, 2000), the likelihood of selfemployment increases with age (Evans and Leighton, 1989a; Brock and Evans, 1986 and Acs, Audretsch and Evans, 1994). One reason for this paradox might be the low amount of capital possessed by young people, inhibiting the start-up of new ventures (OECD, 2000). To stimulate self-employment among young people government policies can support the start-ups of firms by young people financially. Additionally, the government can provide informational support, both through counseling and setting up so-called 'help desks' and building awareness of self-employment as a career option. Moreover, the government can tackle the lack of work experience of young people through the promotion of apprenticeships (during education).

Women are generally less inclined to become entrepreneurs than men and, if they pursue self-employment, they often engage in different activities and start smaller businesses than men (OECD, 2000; Verheul and Thurik, 2001). The fact that female entrepreneurs often start smaller businesses than men can be attributed 
to either different ambitions or activities (Verheul and Thurik, 2001). Women often engage in the service sector, where businesses tend to be smaller. Moreover, it is often argued that women have less financial resources to invest in the business (OECD, 1998b; Hisrich and Brush, 1987; Riding and Swift, 1990). To stimulate entrepreneurship among women and extend their entrepreneurial activities to different sectors of industry the government can support women by giving advice or financial support.

In addition to stimulating entrepreneurial activity of young people and women, the government can also stimulate self-employment among the unemployed through targeted advisory and financial support. In a study by Evans and Leighton (1990) it is found that although unemployed people are about twice as likely as employed people to start a business, these businesses are more likely to fail. Government policies that merely focus on stimulating unemployed people to engage in entrepreneurial activity, thus seem insufficient. Government support in the business phase(s) following the start-up phase, as well as education and training, may raise the chances of small businesses started by unemployed people to survive in the market place.

\section{Stimulating entrepreneurial activity within geographical areas}

Generally, there are large differences in the economic development, living standards and the employment situation between regions within a country (EIM/ENSR, 1997). Government policies can tackle these imbalances by stimulating the establishment of businesses in so-called 'underdeveloped' areas. Urban areas usually attract (small) businesses because the existing infrastructure, consisting of other businesses, financial, advisory and educational institutions. To promote entrepreneurial activity in 'underdeveloped', often rural, areas government policies can focus on developing and sustaining an appropriate infrastructure. In addition, businesses can be granted financial assistance, i.e., subsidies or loans, when moving to less developed areas. Curran and Storey (1993) point out that inducing small business development in accessible rural areas is likely to be rewarded since (manufacturing) firms in these areas tend to outperform the businesses located in urban areas. Policies that are aimed at stimulating entrepreneurship in rural areas however might need to proceed with caution, since they are bound to have consequences. Storey (1994) argues that one of the main concerns of public policy in facilitating the development of small businesses in accessible rural areas is the impact of industrialization on the countryside. Expansion of established businesses and settlement of new businesses in rural areas is often restricted by planning controls that warrant the preservation of these areas.

\section{Stimulating R\&D and high-tech firms}

Technological developments are important for the creation of entrepreneurial opportunities. Government intervention within the area of high-technology firms and $R \& D$ in general is often considered justifiable since market imperfections corrode the extent to which benefits that accrue from technological innovations can be appropriated. Individual inventors can not assure that they (themselves) appropriate the rewards of an invention and this discourages both individual inventors to undertake innovative activities and investors to finance these innovative activities (Storey, 1994). Apart from the risk of 'inappropriability' investments in R\&D are often considered unattractive because of the high risks that accompany these innovative ventures. These risks involve the uncertainty that $R \& D$ investments result in a product that can be sold in the market and the difficulty of assessing the characteristics of the (potential) market (Storey, 1994). On the other hand, the returns on R\&D investments can be very high when these ventures prove to be successful.

Despite the difficulties and risks of innovation for small businesses, a large proportion of R\&D and innovations takes place within small businesses (Menkveld and Thurik, 1999). The government can further stimulate innovative activity in small firms through overcoming market imperfections by supplying finance ${ }^{50}$ in

\footnotetext{
${ }^{50}$ For an overview see Donselaar et al. (2000).
} 
an early stage, i.e., before the product is available for sale, and promoting R\&D through stimulating networks in which knowledge is easily exchanged between businesses and institutions. The problem of 'inappropriability' can be reduced through the implementation of well-designed patent systems that protect the ownership rights of technological innovations.

\subsubsection{Education}

The government can influence the rate of entrepreneurship not solely through legislation, but also through the educational system (EZ, 1999). The government can influence the quality and type of education, through government spending and exposure to quality assessments.

When investigating the impact of education on the level of entrepreneurship in a country a distinction needs to be made between different levels of education: primary (pre-high school), secondary (high school) and tertiary education. Reynolds, Hay and Camp (1999) conclude that the larger a country's investment in education at the tertiary level, the higher is the rate of new firm formation.

Education (in the broadest sense) is important for stimulating entrepreneurship because of several reasons (Reynolds, Hay and Camp, 1999). First, education provides individuals with a sense of autonomy, independence and self-confidence. These qualities are important when starting a business. Second, education makes people aware of alternative career choices. Third, education broadens the horizons of individuals, thereby making people better equipped to perceive opportunities and finally, education provides knowledge that can be used by individuals to develop new entrepreneurial opportunities.

On can distinguish between this general education and more specific education focusing on the promotion of entrepreneurship and stimulating entrepreneurial skills and knowledge. The educational system can be used for the encouragement of commercial awareness, raising the social standing of the entrepreneur and the development of necessary entrepreneurial skills (Gavron, Cowling, Holtham and Westall, 1998). Kourilsky and Carlson (1997) make a similar distinction. In their view entrepreneurship education has multiple goals: creating awareness of entrepreneurship as a career option and of the role of the entrepreneur in the economy, promoting readiness through basic knowledge and (entrepreneurial) qualities and stimulating application of knowledge and qualities in an entrepreneurial context. Implicit in the argument of Kourilsky and Carlson is the 'teachability' of entrepreneurial qualities. Whether and to what degree entrepreneurial qualities can be taught is however a subject of debate in entrepreneurial literature (Gibb, 1993) Van der Kuip (1998) argues that entrepreneurial qualities, perseverance, creativity and risk taking can be developed by introducing projects involving these aspects in both early and later educational phases, ranging from kindergarten to college. These projects may combine teaching elements with practical experience. This approach is in concurrence with Hofstede who argues that "one of the most effective ways of changing mental programs of individuals is changing behavior first" (Hofstede, 1980, p. 23). In addition, universities (tertiary education) can provide courses on entrepreneurship, enabling the development of practical business skills. Moreover, universities could incorporate business modules into their regular curriculum (OECD, 1998a).

Beyond training of entrepreneurial skills, education can transmit entrepreneurial values and can influence the attitude of people towards entrepreneurship (OECD, 1998a). At the same time, a more positive societal attitude towards entrepreneurship may stimulate entrepreneurial education, because education is also an expression of the prevailing cultural values. In this sense culture and education are intertwined. On this mutual reinforcement between education and culture also see Hofstede (1980, p. 22 and p. 233). This topic will be further discussed in section 9 . 


\subsection{Five types of government intervention framing entrepreneurial activity}

In previous sections the impact of government policy on entrepreneurship has been dealt with using a typology based on traditional perspectives in the literature. Earlier in this paper a distinction has been made between five types of government intervention. These types of government intervention correspond with the dotted arrows in Figure 1 and represent the influence of government policy on entrepreneurial activity through the different determinants of entrepreneurship. The aim of this section is to discuss these five types of government intervention and thereby create better insight into the processes by which the government can have impact on the rate of entrepreneurial activity.

"Type 1" government intervention, as represented by arrow "G1" in Figure 1, involves government intervention on the demand side of entrepreneurship - government intervention that (in)-directly impacts the type, number and accessibility of entrepreneurial opportunities. Some of these policies help to create demand for entrepreneurship whereas others enable small firms to make use of the room that is created by market demand. Policies stimulating technological developments and income policy belong to the first category of policies, whereas competition policy and establishment legislation pertain to the latter category of policies. Technological advancements create opportunities for entrepreneurial ventures through new ideas or new application processes. These advancements can be stimulated by the government through (subsidizing) expenditures on R\&D. Income policy can create opportunities for entrepreneurship through higher wealth or income disparity, inducing demand for tailor-made products and services and thereby stimulating demand for entrepreneurship. Competition policy improves the accessibility of markets through reducing market power of large firms and lowering barriers to entry for small businesses. Moreover, establishment legislation tends to negatively influence the access to markets, through the implementation of business licensing requirements.

When comparing the elements of "type 1" intervention with traditional perspectives on government intervention as distinguished in the previous section, there is little similarity. Income policy is generic, focusing on all households within the economy, whereas other policies, in particular R\&D subsidies, are more specific. However, competition policy and establishment legislation can both be related to deregulation and simplification, influencing the access to the market.

"Type 2" government intervention, as represented by arrow "G2" in Figure 1, involves government intervention to affect the pool or supply of potential entrepreneurs at the aggregate level. These policies can take the form of influencing the characteristics or the number of people within the population. Policies that pertain to "type 2" intervention include immigration policy and regional development policy (dealing with (sub)urbanization processes), influencing the composition and the dispersion of the population, respectively. Moreover, the fiscal treatment of families with children, including family allowances or child benefits, may influence the age composition of the population.

"Type 3" government intervention, as represented by arrow "G3" in Figure 1, impacts the availability of resources, skills and knowledge of potential entrepreneurs. Resources, skills and knowledge are all internal individual characteristics that can be acquired or further developed through training or education. Inborn characteristics, such as learning capacity and personality traits, are far less likely, if not impossible, to be developed through education and training. Government policy will have to focus on, for instance, overcoming the finance and knowledge gap through increasing the availability of financial and informational resources, respectively. For example, policies aimed at the (development of the) venture capital market can help improving the access of (small) business owners to financial capital needed to start or expand a business. Direct financial support, i.e., subsidies, grants and loan guarantees, can also increase the availability of resources of (potential) entrepreneurs. The knowledge base, consisting of both skills and knowledge, of the (potential) entrepreneur can be influenced through the direct provision of relevant 'business' information, i.e., advice and counseling, or through the educational system. "Type 3" policies can be typified as input-related 
policies, since they refer to both material, i.e., financial capital, and immaterial, i.e., knowledge, inputs in the entrepreneurial process.

"Type 4" government intervention, as represented by arrow "G4" in Figure 1, works through the preferences of individuals to become an entrepreneur. Preferences of people, as expressed through values and attitudes, are developed during upbringing. Although preferences are culturally determined, the government can play a role, albeit small, in shaping entrepreneurial values and attitudes by introducing entrepreneurial elements in the educational system and by paying attention to entrepreneurship in the media. "Type 4" policies are characterized by the assumed broadness of the concept of government policy, including the educational system and overlapping, to some extent, with culture. The relationships between culture, institutions and entrepreneurship are the subject of the next section.

"Type 5" government intervention, as represented by arrow "G5" in Figure 1, is directed at the decisionmaking process of individuals, i.e., potential entrepreneurs. Given opportunities, resources, ability, personality traits and preferences, the risk-reward profile of entrepreneurship can be influenced by this type of government intervention. Policies that are relevant in this respect, are taxation, influencing business earnings, social security arrangements, influencing the willingness of people to give up their present state of (un)employment to become an entrepreneur, and labor market legislation regarding hiring and firing, thereby determining the flexibility of the business and the attractiveness to start or continue a business. Bankruptcy policy can also influence the risk-reward profile. For example, when legal consequences of bankruptcy are severe, this may lead people to shy away from self-employment. Note that "type 5" policies are generic macro economic policies, as they apply to all economic actors.

\section{Culture}

\subsection{Defining culture}

A variety of definitions of culture exists (Kluckhohn, 1951; Schneider and Barsoux, 1997, p. 19). In the present paper we use the definition as proposed by Hofstede $(1991$, p. 5) who defines culture as "the collective programming of the mind which distinguishes the members of one group or category of people from another". This definition may be applied to different levels of analysis, including the level of the family, ethnic group, firm or other organization and society or nation.

Culture is intangible and largely unobservable as it can only be studied through various verbal and nonverbal manifestations from which constructs are inferred (Hofstede, 1980, p. 14). Culture is a highly complex phenomenon, including both deeply embedded values and manifestations that are more at the surface and consequently more observable. The different levels of culture are illustrated in Figure 3. 
Figure 3: Manifestations of culture at different levels

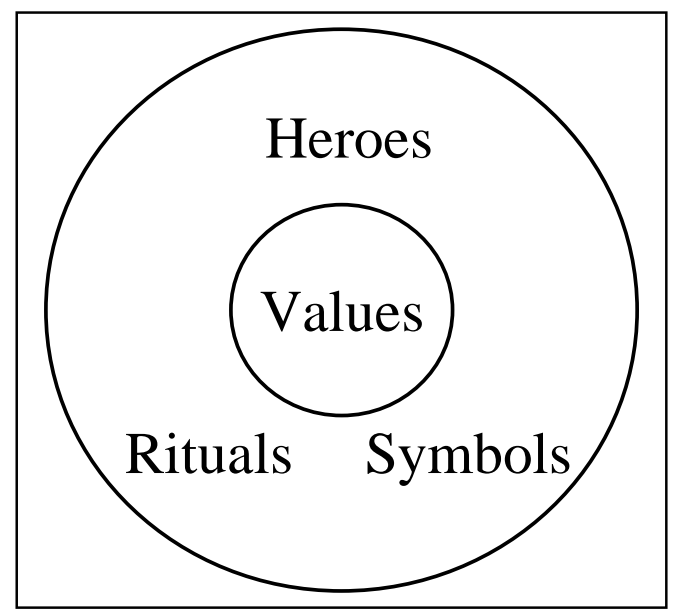

Source: Hofstede (1991, p. 9).

Values are the most deeply embedded manifestations. Hofstede (1980, p. 18) defines values as "a broad tendency to prefer certain states of affairs over others" ${ }^{21}$. Rituals, heroes and symbols are more outwarddirected manifestations.

For a better understanding of the concept of culture it is necessary to make a distinction between culture and personality. The latter refers to the individual and encompasses personal traits ${ }^{52}$, originating from genetic inheritance and individual experiences, as well as values that are for a large part shaped by cultural influences. In contrast, culture is restricted to collective, often normative, 'mental programs'. There is an ongoing debate among psychologists to what extent culture and personality can be considered independent and distinct variables, and to what extent they are 'mutually constitutive', i.e., integral parts (Church, 2000). In his study Church propagates an integrated cultural trait psychology perspective (Church, 2000, p. 681). This means that he argues that mental programming is partly unique for individuals and partly shared with those who belong to the same culture.

For research on the determinants of entrepreneurship it is useful to make a distinction between culture and institutions (Mitchell, 1979, p. 107; Wennekers and Thurik, 1999, p. 41). We consider culture mainly as unobservable and institutions as observable. Here we differ from North (1994, p. 360) who subsumes culture under institutions ${ }^{53}$. A related distinction is the one between background institutions, that are predominantly cultural, such as trust, commitment and authority relationships, and social institutions, that are related to business organizations, such as property rights, capital markets and the education system (Whitley, 1992, p. 19-25 and p. 269). In the present paper a distinction has been made between culture, general institutions and specific policies that support new and/or small firms.

\subsection{Measuring culture}

We claim that culture can only be indirectly inferred from its manifestations: rituals, symbols, heroes and values (see Figure 3). Rituals, symbols and heroes can be studied through content analysis of documents,

${ }^{51}$ Some well-known values are individualism versus collectivism, power distance, social implications of gender, trust, ways of dealing with uncertainty and the valuation of wealth.

52 The most important personality traits that are distinguished in the literature are extraversion, agreeableness, conscientiousness, emotional stability and openness towards (new) experiences. These traits are often referred to as the "big five" (Church, 2000, p. 655).

53 "Institutions are the humanly devised constraints that structure human interaction. They are made up of formal constraints (rules, laws, constitutions), informal constraints (e.g., norms of behavior, conventions, self-imposed codes of conduct), and their enforcement characteristics. Together they define the incentive structure of societies and specifically economies". 
speeches, television programs and other recorded material. Values are often studied through surveys in which individual people are interviewed about their preferences and opinions. Inferences about differences in values between groups can be made by comparison of the mean scores of the interviewed individuals from these groups ${ }^{54}$. Alternatively, the extremes of the frequency distributions can be compared.

The most famous systematic attempt to measure cultural differences between nations is made by Hofstede (1980) who analyzed the empirical data of an exceptionally large survey of IBM subsidiaries in 40 countries in 1968 and 1972. A factor analysis of the mean scores per country regarding work-related values produced four dimensions of national culture: individualism, power distance, masculinity and uncertainty avoidance. In a later study (Hofstede, 1991) long term orientation was added as a fifth dimension.

Other cross-national empirical studies have been conducted by Inglehart (1997) who studied the rise of 'postmaterialist' values, Hoppe (1990) who carried out a study similar to the one by Hofstede, and Lynn (1991) who studied different national attitudes to competitiveness and money.

\subsection{Cultural change}

\subsubsection{Values}

Values change slowly. Hofstede (1980, p. 16) stresses that mental programs passed on from one generation to another are resistant to change. He emphasizes that the stability of cultural patterns can be ascribed to "reinforcement by the institutions which themselves are products of the dominant value systems" (Hofstede, 1980, p. 233). These institutions "include the family, education systems, politics and legislation" (Hofstede, 1980 , p. 22). The role of historical processes in shaping cultural value orientations is also shown in an indepth three country study by d'Iribarne, focusing on management and culture in France, the United States and the Netherlands (1989, chapters 2, 5 and 8). It highlights the role of path dependence.

Hofstede (1980) makes a distinction between three processes of cultural change: zeitgeist effects (values shift due to external shocks, such as a technological revolution, war or recession); generation effects (generations differing in fixed values replace each other) and maturation or seniority effects (respondents' values change as they grow older or assume greater responsibilities).

The process of cultural change in society can be demonstrated by focusing on the changing value systems. According to Hofstede (1980) the period between 1968 and 1972 showed a sharp increase in individualism, a slight increase in masculinity and stress at work, and a decreasing preference for an autocratic boss. These cultural trends are worldwide but there is little evidence of cultural convergence across countries, with the possible exception of individualism (Hofstede, 1991, p. 238). From a long-term perspective, the strong statistical impact of rising wealth on individualism (Hofstede, 1991, p. 75) makes a continued trend towards individualism highly likely, with emerging high-growth economies converging towards the level of individualism attained in the rich countries.

\subsubsection{Positive feedback from increasing self-employment}

Although culture is slow to change entrepreneurial activity may create its own feedback cycle, slowly moving society to a more entrepreneurial culture. In regions or countries with a high density of entrepreneurial activity examples of successful new venture creation offer role models people can conform to: "If he/she can do it, I can" (Veciana, 1999). A "demonstration" principle is at work here: the more entrepreneurs, the higher the

\footnotetext{
${ }^{54}$ It must be noted that groups may show a large degree of variation as cultural typologies only describe central tendencies or dominant values.
} 
exposure of people to entrepreneurship, the higher the acceptance of entrepreneurship as an alternative to wage-employment and the higher the likelihood of other people becoming self-employed.

In the past twenty years positive feedback effects from re-emerging entrepreneurial role models, reinforced by changes in incentive structures and other institutional changes, may have contributed to the rise of entrepreneurial preferences and abilities. Given the early stage of institutional change and the slow pace of cultural change through generation replacement ${ }^{55}$ it is reasonable to expect a further increase in entrepreneurship in the next years ${ }^{56}$.

\subsection{Culture's consequences}

\subsubsection{Culture matters}

There is an extensive literature on the importance of culture and institutions for economic structure and performance. The role of culture has been analyzed at the macro level (Landes, 1998; Lynn, 1991; North, 1990 and 1994 and Olson, 1982 and 1996) and the firm level (Casson, 1991; Hofstede, 1991 and Whitley, 1992). In this section we will focus on culture's implications for the level of entrepreneurship, i.e., business ownership, in a country.

\subsubsection{Culture and entrepreneurship}

From the framework proposed in section three (Figure 1) it can be inferred that national culture may influence the level of entrepreneurship through both the supply and the demand side of entrepreneurship. At the supply side individual preferences for self-employment are likely to be within the cultural domain, since they are often shaped by the nation's prevailing attitude towards entrepreneurship. In a study of Reynolds et al. (1999) several indicators of an entrepreneurial culture are mentioned. At the level of symbols, rituals and heroes (Figure 4) both the stories in the media about successful entrepreneurs and the respect for those who start a new business may be indicators of an entrepreneurial culture. In a sample of ten countries a positive correlation was found between respect for entrepreneurs and the rate of firm start-ups (Reynolds et al., 1999, p. 30$)^{57}$. At the level of more deeply rooted values the following values are found to be important for entrepreneurship: the value placed on independence and autonomy in the workplace, tolerance for inequality of income and wealth and the (absence of) stigma attached to those whose entrepreneurial initiatives fail. Reynolds et al. (1999) find a positive empirical relationship between the social value of independence and the level of entrepreneurial activity. However, at the level of values relationships between culture and entrepreneurship do not always follow intuition. This is demonstrated in a cross-sectional study by Wildeman et al. (1999) reporting an unexpected positive relationship between Hofstede's power distance and uncertainty avoidance indices and the share of business ownership in the labor force in 23 industrial nations. Additionally they find a negative correlation with Hoppe's individualism index. They explain these results as proof that dissatisfaction can be a source of entrepreneurship: in countries with a high power distance, a high uncertainty avoidance and low individualism, there may be relatively more business owners since enterprising individuals cannot satisfy their needs within existing organizations. Support for this hypothesis can be found in Baum et al. (1993) where it is argued that there is a negative impact of individualism on the level of entrepreneurship. On the other hand, uncertainty avoidance has also been shown to have a negative indirect

\footnotetext{
${ }^{55}$ Reynolds (2000, p. 48) also expects that "Fundamental changes in the life course, occupational, and career aspirations of ordinary citizens, required to create an enterprise society, may take several human generations".

${ }^{56}$ However, these reinforcement feedbacks may not continue indefinitely. When the percentage of entrepreneurs in the labor force is very high, the opportunities for potential entrepreneurs may decrease. Moreover, competition between the increasing number of incumbent entrepreneurs may in time lead to a high exit rate. These effects will be strengthened if the carrying capacity of the market diminishes as more products of the present technological wave mature and scale economies arise

${ }^{57}$ This may be an example of a positive feedback effect as mentioned in the previous section.
} 
influence on the development of the level of entrepreneurship over time. In a study by Noorderhaven et al. (1999) Hofstede's uncertainty avoidance index is used to make a distinction between high and low uncertainty avoidance countries. In the former group a strong negative relationship between GDP per capita and the level of business ownership is found, indicating that push factors to entrepreneurship prevail in this environment. For the low uncertainty avoidance countries no significant influence of per capita income on business ownership is found. However, the expected profits of self-employment appear to be a significant pull factor for entrepreneurship. Almost all of the low uncertainty avoidance countries show a resurgence of business-ownership in recent years ${ }^{58}$.

The influence of culture, through the supply side dimension of entrepreneurial abilities, is difficult to establish and remains rather speculative. However, prevailing attitudes with respect to entrepreneurship in the educational system will probably influence the degree of relevant training that is offered in schools. The evaluation report ${ }^{59}$ of the Australian program on entrepreneurship and education gives strong indications that the presence of a principal or teacher who is highly committed to the concept of enterprise education is a key factor for schools in becoming involved in enterprise education projects.

Culture may also influence entrepreneurship through the demand side as it (indirectly) influences entrepreneurial opportunities. The prevalence of entrepreneurial values within the realm of government and politics may influence the scope of the private versus the social sector, particularly with respect to utilities and personal services; the degree of entry regulation of new business start-ups and the extent to which innovative regional clusters are fostered through private-public partnerships.

In sum little is still known about the complex role of culture in the rise and fall of business-ownership. More extensive and international comparable data regarding cultural dimensions at the country level are needed to create a better understanding of the influence of culture on entrepreneurship and the relevant social and economic processes involved.

\section{Conclusions}

The level of entrepreneurship differs considerably across countries and periods. Entrepreneurship is a multidimensional concept, the definition of which depends largely on the focus of the research undertaken. The present study deals with the factors determining the level of entrepreneurship. A broad range of determinants explains the level of entrepreneurship, including economic and social factors. Moreover, it is generally accepted that policy measures can influence the level of entrepreneurship. The government can exert influence on entrepreneurship in different ways; directly through specific measures and indirectly through generic measures. For example, when stipulating a competition policy, the government can influence the market structure and (indirectly) the number and type of entrepreneurial opportunities.

The goal of the present paper is threefold. First, it attempts to integrate different perspectives of the determinants of entrepreneurship. Second, an extensive description of the role of government is provided in an endeavor to answer the question of how policy measures may influence entrepreneurship. Third, our model may serve as means for explaining temporal en cross-sectional differences in the rate of entrepreneurship. The paper is motivated by the recent increase in the rate of entrepreneurship in many modern economies, by the considerable variation of this rate across countries and the importance of entrepreneurship for growth.

\footnotetext{
${ }^{58}$ Given these mixed results of cross-sectional and (indirect) time-series analysis of the impact of uncertainty avoidance on the level of entrepreneurship, one might hypothesize that the worldwide trend towards individualism has also had a positive (indirect) effect on the revival of business-ownership.

${ }^{59}$ Keys Young, Evaluation of the enterprise education in schools (EES) element of the school to work programme; final report, 24 June 1999, Department of Education, Training and Youth Affairs, Canberra.
} 
The level of entrepreneurship in a particular country can be explained making a distinction between the supply side (labor market perspective) and the demand side (product market perspective; carrying capacity of the market) of entrepreneurship. This distinction is sometimes referred to as that between push and pull factors. The determinants of entrepreneurship can also be studied according to level of analysis. A distinction can be made between the micro, meso and macro level of entrepreneurship. The objects of study tied to these levels of analysis, are the individual entrepreneur or business, sectors of industry and the national economy, respectively. Studies at the micro level focus on the decision-making process by individuals and the motives of people to become self-employed. Research into the decisions of individuals to become either wage- or self-employed focuses primarily on personal factors, such as psychological traits, formal education and other skills, financial assets, family background and previous work experience. Studies at the meso level of entrepreneurship often focus on market-specific determinants of entrepreneurship, such as profit opportunities and opportunities for entry and exit. The macro perspective focuses on a range of environmental factors, such as technological, economic and cultural variables as well as government regulation.

The present study focuses on the country level of analysis, but attempts to explicitly link the country level to the micro level where an individual's risk-reward profile represents the process of weighing alternative types of employment. This profile is based on opportunities (environmental characteristics), resources, ability, personality traits and preferences (individual characteristics). The occupational choices of individuals are made on the basis of their risk-reward profile of entrepreneurship versus that of other types of employment, such as wage employment or unemployment. At the aggregate level these occupational choices emerge as entry and exit rates of entrepreneurship. Weighing alternative types of employment people can trade in their wage jobs (or unemployment) for self-employment, i.e., entry into entrepreneurship, they can remain within the type of employment they are currently in or they can decide, either voluntarily or involuntarily, to exit from self-employment.

The process of occupational choice is also embedded in an institutional and cultural environment. First, opportunities for entrepreneurial activity depend upon the development of the private service sector versus the public provision of services and the evolution of the household and the so-called informal sector. Since the late 1980s the balance has shifted towards commercial provision of many services due to privatization, deregulation and a decreasing tax and social security wedge in many countries. Additionally, entrepreneurial opportunities also depend upon competition and establishment legislation. Second, the government can influence resources and abilities of individuals through subsidized information and advice services, loan guarantees and other direct support schemes. Third, personal attitudes towards entrepreneurship are a 'product' of the current cultural environment. These cultural patterns are however stable and path dependent, and are reinforced by education and legislation that again are products of the cultural system. Nonetheless, once policies promoting entrepreneurial opportunities, the availability of resources and entrepreneurial ability bear some success, emerging entrepreneurial activity will provide new role models triggering cultural change.

This paper has documented that entrepreneurship is a multi-faceted phenomenon. This may explain why research on entrepreneurship spans so many academic fields under many disparate guises. At its best, the subject has generated a diversity of approaches and perspectives. At its worse, it has a Tower of Babel nature, where each academic discipline speaks its own distinct language with its own methodology, impenetrable by outsiders.

This paper has tried to build on the positive challenges of entrepreneurship research by drawing on the rich traditions and findings spanning a broad spectrum of academic disciplines to develop an integrated eclectic theory of entrepreneurship. This eclectic theory incorporates multi-level units of analysis - micro (individuals) as well as macro (countries). In addition, it draws on the perspectives and traditions of a number of 
disciplines, including sociology, management, psychology, regional science, and economics. The resulting eclectic theory ought to provide a conceptual framework for analyzing both the determinants of entrepreneurship as well as the consequences or impact of entrepreneurship across a broad array of industry, national, spatial and temporal settings. Hopefully, this eclectic entrepreneurship theory will serve as a bridge to provide a common link across the broad array of academic disciplines, reflecting the rich diversity of settings in which entrepreneurship takes place.

\section{Literature}

Acemoglu, D., 1995, Reward structures and the allocation of talent, European Economic Review 39 (1), 1733.

Acs, Z.J., D.B. Audretsch and D.S. Evans, 1994,

The determinants of variations in self-employment rates across countries and over time, mimeo.

Acs, Z.J. and D.B. Audretsch, 1987, Innovation, market structure, and firm size, Review of Economics and Statistics 69 (4), 567-574.

Acs, Z.J. and D.B. Audretsch, 1993, Conclusion, in: Z.J. Acs and D.B. Audretsch (eds), Small Firms and Entrepreneurship: an East-West Perspective, Cambridge University Press, Cambridge, 227-231.

Acs, Z.J., B. Carlsson, and C. Karlsson, 1999, Entrepreneurship, Small and Medium-Sized Enterprises and the Macroeconomy, Cambridge University Press, Cambridge.

Audretsch, D.B. and M. Fritsch, 2000, Geography of firm births in Germany, Regional Studies 28 (4), 359365.

Audretsch, D.B. and M.P. Feldman, 1996, R\&D spillovers and the geography of innovation and production, American Economic Review 86 (3), 630-640.

Audretsch, D.B. and P.E. Stephan, 1996, Company-scientist locational links: the case of biotechnology, American Economic Review 86 (3), 641-652.

Audretsch, D.B. and A.R. Thurik, 1998, The knowledge society, entrepreneurship and unemployment, Research Report 9801/E, EIM Business and Policy Research, Zoetermeer.

Audretsch, D.B. and A.R. Thurik, 2000, Capitalism and democracy in the 21st century: from the managed to the entrepreneurial economy, Journal of Evolutionary Economics 10 (1), 17-34.

Audretsch, D.B. and A.R. Thurik, 2001, What is new about the new economy: sources of growth in the managed and entrepreneurial economies, Industrial and Corporate Change, 2001, forthcoming.

Audretsch, D.B., M.A. Carree, A.J. van Stel and A.R. Thurik, 2000, Impeded industrial restructuring: the growth penalty, Discussion paper, Tinbergen Institute, Erasmus University Rotterdam, forthcoming.

Baenen, N.M.A. and F.J.W. Visser, 1996, Social security for the self-employed in Belgium, Germany, the United Kingdom and the Netherlands, Strategic Study B9608, EIM Business and Policy Research, Zoetermeer.

Bais, J., W.H.M van der Hoeven and W.H.J. Verhoeven, 1995, Determinanten van zelfstandig ondernemerschap: een internationale vergelijking, OSA-werkdocument, Den Haag.

Bates, T., 1997, Race, Self-Employment and Upward Mobility, Johns Hopkins University Press, Baltimore.

Baum, J.R., J.D. Olian, M. Erez, E.R. Schnell, K.G. Smith, H.P. Sims, J.S. Scully and K.A. Smith, 1993, Nationality and work role interactions: a cultural contrast of Israeli and U.S. entrepreneurs' versus managers' needs, Journal of Business Venturing 8 (6), 499-512.

Baumol, W.J., 1990, Entrepreneurship: productive, unproductive and destructive, Journal of Political Economy 98 (5), 893-921.

Borooah, V.K. and M. Hart, 1999, Factors affecting self-employment among Indian and black Caribbean men in Britain, Small Business Economics 13 (2), 111-129.

Birley, S. and P. Westhead, 1994, A taxonomy of business start-up reasons and their impact on firm growth and size, Journal of Business Venturing 9 (1), 7-31.

Blanchflower, D.G., 2000, Self-employment in OECD countries, Labour Economics 7, 471-505.

Blanchflower, D.G. and B.D. Meyer, 1994, A longitudinal analysis of the young self-employed in Australia and the United States, Small Business Economics 6 (1), 1-19.

Blanchflower, D.G. and A.J. Oswald, 1998, What makes an entrepreneur?, Journal of Labor Economics 16 (1), 26-60.

Blau, D., 1987, A time-series analysis of self-employment in the United States, Journal of Political Economy 95 (3), 445-467.

Borger, J.C., N.L.C.M. Janssen and E.A. van Noort, 2000, The venture capital market for SMEs: an international perspective, EIM Business and Policy Research, Zoetermeer.

Bosch, L.H.M. and F.M.J. Westhof, 1997, Sociale zekerheid en ondernemerschap, Strategische Verkenning B9710, EIM Business and Policy Research, Zoetermeer. 
Bosma, N.S., A.R.M. Wennekers and W.S. Zwinkels, 1999, Scanning the future of entrepreneurship, Research Report 9901/E, EIM Business and Policy Research, Zoetermeer.

Bosma, N.S., W.S. Zwinkels and M.A. Carree, 1999, Determinanten voor toe- en uittreding van ondernemers: een analyse van de ontwikkelingen in Nederland over de periode 1987-1997, EIM Business and Policy Research, Zoetermeer.

Bosma, N.S. and H.R. Nieuwenhuijsen, 2000, Turbulence and productivity in the Netherlands, Research Report 9909/E, EIM Business and Policy Research, Zoetermeer.

Bosma, N.S., A.R.M. Wennekers, G. de Wit and W.S. Zwinkels, 2000, Modelling business ownership in the Netherlands, Research Report 9911/E, EIM Business and Policy Research, Zoetermeer.

Bregger, J.E., 1996, Measuring self-employment in the United States, Monthly Labor Review, January/February, 3-9.

Brock, W.A. and D.S. Evans, 1989, Small Business Economics, Small Business Economics 1 (1), 7-20.

Brock, W.A. and D.S. Evans, 1986, The Economics of Small Businesses: Their Role and regulation in the U.S. Economy, Holmes and Meier, New York.

Brockhaus, R.H., 1982, The psychology of the entrepreneur, in: C.A. Kent, D.L. Sexton and K.H. Vesper (eds), Encyclopedia of Entrepreneurship, Prentice-Hall, Englewood Cliffs.

Brockhaus, R.H., 1980a, The effect of job dissatisfaction on the decision to start a business, Journal of Small Business Management 18 (1), 37-43.

Brockhaus, R.H., 1980b, Risk taking propensity of entrepreneurs, Academy of Management Journal 23 (3), 509-520.

Brown C., J. Hamilton en J. Medoff, 1990, Employers Large and Small, MA: Harvard University Press, Cambridge.

Bruce, D., 1999, Do husbands matter? Married women entering self-employment, Small Business Economics 13 (4), 317-329.

Brüderl, J. and P. Preisendörfer, 1998, Network support and the success of newly founded businesses, Small Business Economics 10 (3), 213-225.

Brush, C.G., 1992, Research on women business owners: past trends, a new perspective and future directions, Entrepreneurship Theory and Practice 17 (4), 5-30.

Bull, I. and G.E. Willard, 1993, Towards a theory of entrepreneurship, Journal of Business Venturing 8, 183195.

Buttner, E.H. and D.P. Moore, 1997, Women's organizational exodus to entrepreneurship: self-reported motivations and correlates with success, Journal of Small Business Management 35 (1), 34-46.

Buttner, E.H. and B. Rosen, 1989, Funding new business ventures: are decision makers biased against women entrepreneurs?, Journal of Business Venturing 4 (4), 249-261.

Carlsson, B., 1989, The evolution of manufacturing technology and its impact on industrial structure: an international study, Small Business Economics 1 (1), 21-38.

Carlsson, B., and E. Taymaz, 1994, Flexible technology and industrial structure in the U.S., Small Business Economics 6 (3), 193-209.

Carree, M.A., 1997, Market Dynamics, Evolution and Smallness, Thesis Publishers and Tinbergen Institute, Amsterdam.

Carree, M.A. and J. Nijkamp, 2001, Deregulation in retailing: the Dutch experience, Journal of Economics and Business, forthcoming.

Carree, M.A. and A.R. Thurik, 2000a, Market structure dynamics and economic growth, in: G. Galli and J. Pelkmans (eds), Regulatory Reform and Competitiveness in Europe no. 1: Horizontal Issues, Edward Elgar Publishing, Cheltenham (U.K.), 430-460.

Carree, M.A. and A.R. Thurik, 2000b, The life cycle of the U.S. tire industry, Southern Economic Journal 67 (2), 254-278.

Carree, M.A., and A.R. Thurik, 1999, Industrial structure and economic growth, in: D.B. Audretsch and A. R. Thurik (eds), Innovation, Industry Evolution and Employment, Cambridge University Press, Cambridge, $86-110$.

Carree, M.A., and A.R. Thurik, 1998, Small firms and economic growth in Europe, Atlantic Economic Journal 26 (2), 137-146.

Carree, M.A., and A.R. Thurik, 1996, Entry and exit in retailing: incentives, barriers, displacement and replacement, Review of Industrial Organization 11 (2), 155-172.

Carree, M.A., A. van Stel, A.R. Thurik and A.R.M. Wennekers, 2001, Economic development and business ownership: an analysis using data of 23 modern economies in the period 1976-1996, Small Business Economics, 2001, forthcoming.

1999, Business ownership and economic growth in 23 OECD countries, Discussion paper TI00-001/3, Tinbergen Institute, Erasmus University Rotterdam.

Casson, M., 1991, The Economics of Business Culture, Clarendon Press, Oxford. 
Casson, M., 1995, Entrepreneurship and Business Culture; Studies in the Economics of Trust, vol.1, Edward Elgar Publishing, Cheltenham (U.K.).

Chandler, A., 1990, Scale and Scope: The Dynamics of Industrial Capitalism, Harvard University Press, Cambridge.

Chandler, A., 1977, The Visible Hand: The Managerial Revolution in American Business, Harvard University Press, Cambridge.

Church, A.T., 2000, Culture and personality: toward an integrated cultural trait psychology, Journal of Personality 68 (4), 651-703.

Clark, K. and S. Drinkwater, 2000, Pushed out or pulled in? Self-employment among ethnic minorities in England and Wales, Labour Economics 7, 603-628.

Cressy, R.C., 1996, Commitment lending under asymmetric information: theory and tests on UK start-up data, Small Business Economics 8 (5), 397-408.

Curran, J. and D.J. Storey, 1993, The location of small and medium enterprises: are there urban/rural differences?, in: J. Curran and D.J. Storey (eds), Small Firms in Urban and Rural Locations, Routledge, London.

Darlington, G., 1996, Culture: a theoretical review, in: P. Joynt and M. Warner (eds), Managing Across Cultures: Issues and Perspectives, International Thomson Business Press, London.

Davis, S.J. and M. Henrekson, 1999, Explaining national differences in the size and industry distribution of employment, Small Business Economics 12 (1), 59-83.

Donselaar, P., H. Nieuwenhuijsen, J. van Sinderen and J. Verbruggen, 2000, Economische effecten van R\&D-stimulering bij bedrijven, Beleidsstudies Technologie Economie No. 36, Ministerie van Economische Zaken, Den Haag.

Dutz, M.A., J.A. Ordover and R.D. Willig, 2000, Entrepreneurship, access policy and economic development: lessons from industrial organization, European Economic Review 44 (4), 739-747.

EIM/ENSR, 1993, The European Observatory for SMEs; first annual report, EIM Business and Policy Research, Zoetermeer.

EIM/ENSR, 1995, The European Observatory for SMEs; third annual report, EIM Business and Policy Research, Zoetermeer.

EIM/ENSR, 1996, The European Observatory for SMEs; fourth annual report, EIM Business and Policy Research, Zoetermeer.

EIM/ENSR, 1997, The European Observatory for SMEs; fifth annual report, EIM Business and Policy Research, Zoetermeer.

Evans, D.S. and B. Jovanovic, 1989, An estimated model of entrepreneurial choice under liquidity constraints, Journal of Political Economy 97 (4), 808-827.

Evans, D.S. and L.S. Leighton, 1990, Small business formation by unemployed and employed workers, Small Business Economics 2 (4), 319-330.

Evans, D.S. and L.S. Leighton, 1989a, The determinants of changes in U.S. self-employment, 1968-1987, Small Business Economics 1 (2), 111-119.

Evans, D.S. and L.S. Leighton, 1989b, Some empirical aspects of entrepreneurship, American Economic Review 79 (3), 519-535.

EZ, 1999, The entrepreneurial society. Entrepreneurship: more opportunities, less threats, Ministry of Economic Affairs, Den Haag.

Fiet, J.O., 1996, The informational basis of entrepreneurial discovery, Small Business Economics 8 (6), 419430.

Gaston, R.J., 1989, The scale of informal capital markets, Small Business Economics, 1 (3), 223-230.

Gavron, R., M. Cowling, G. Holtham and A. Westall, 1998, The Entrepreneurial Society, Institute for Public Policy Research, London.

Gelderen, M.W. van, 1999, Ontluikend ondernemerschap (Nascent Entrepreneurship), Strategische Verkenning B9807, EIM Business and Policy Research, Zoetermeer.

Gibb, A.A., 1993, The enterprise culture and education. Understanding enterprise education and its links with small business, entrepreneurship and wider educational goals, International Business Journal 11 (3), 11-34.

Griliches, Z. and C. Hjorth-Andersen, 1992, The search for R\&D spillovers; comment, Scandanavian Journal of Economics 94, S29-47.

Gompers, P., 1999, The Venture Capital Cycle, MA: MIT Press, Cambridge.

Hébert, R.F. and A.N. Link, 1989, In search of the meaning of entrepreneurship, Small Business Economics 1 (1), 39-49.

Henrekson, M., 2000, Personal taxation and the scope for entrepreneurial activity, Paper presented at the Jönköping International Workshop on "Institutions, Entrepreneurship and Firm Growth", 13-15 January 2000. 
Henrekson, M. and D. Johansson, 1999, Institutional effects on the evolution of the size distribution of firms, Small Business Economics 12 (1), 11-23.

Hisrich, R.D. and C.G. Brush, 1987, Women entrepreneurs: a longitudinal study, in: N.C. Churchill, J.A. Hornaday, B.A. Kirchhoff, O.J. Krasner and K.H. Vesper (eds), Frontiers in Entrepreneurship Research, Babson College, Wellesley, 187-199.

Hofstede, G., 1991, Cultures and Organizations: Software of the Mind, McGraw-Hill, London.

Hofstede, G., 1980, Culture's Consequences: International Differences in Work-Related Values, Sage, Beverly Hills.

Hoppe, M.H., 1990, A comparative study of country elites: international differences in work-related values and learning and their inplications for international management training and development, PhD thesis, University of North Carolina, Chapel Hill.

Ilmakunnas, P., V. Kanniainen and U. Lammi, 1999, Entrepreneurship, economic risks, and risk-insurance in the welfare state, Discussion papers No. 453, Department of Economics, University of Helsinki.

Inglehart, R., 1997, Modernization and Postmodernization: Cultural, Economic and Political Change in 43 Societies, NJ: Princeton University Press, Princeton.

International Labor Organisation (ILO), 1990, The Promotion of Self-Employment, ILO, Geneva.

Iribarne, Ph. d', 1998, Eer, Contract en Consensus; Management en Nationale Tradities in Frankrijk, de Verenigde Staten en Nederland (Dutch translation), Uitgeverij Nieuwezijds, Amsterdam.

lyigun, M.F. and A.L. Owen, 1988, Risk, entrepreneurship, and human-capital accumulation, AEA Papers and Proceedings 88 (2), 454-457.

Jackson, L.F., 1984, Hierarchic demand and the Engle curve for variety, Review of Economics and Statistics $66(1), 8-15$.

Jensen, M.C., 1993, The modern industrial revolution, exit, and the failure of internal control systems, Journal of Finance 48 (3), 831-880.

Jovanovic, B., 1993, The diversification of production, Brooking Papers: Microeconomics, 197-235.

Kalleberg, A.L. and K.T. Leicht, 1991, Gender and organizational performance: determinants of small business survival and success, Academy of Management Journal 34 (1), 136-161.

Klepper, S. and K.L. Simons, 1999, Dominance by birthright: entry of prior radio producers and competitive ramifications in the U.S. television receiver industry, Paper presented at the EARIE Conference, version October 1999, Turin.

Klepper, S., 1996, Entry, exit, growth, and innovation over the product life cycle, American Economic Review 86 (3), 562-583.

Kluckhohn, C., 1951, The study of culture, in: D. Lerner and H.D. Lasswell (eds), The Policy Sciences, CA: Stanford University Press, Stanford.

Koning, A. de, 1998, Business failures and entrepreneurship in international perspective, Dutch SMEs in international perspective, A9816, EIM Business and Policy Research, Zoetermeer.

Koning, A. de and J. Snijders, 1992, Policy on small and medium-sized enterprises in countries of the European Community, International Small Business Journal 10 (1), 25-39.

Kourilsky, M.L. and S.R. Carlson, 1997, Entrepreneurship education for youth: a curicular perspective, in: D.L. Sexton and R.W. Smilor (eds), Entrepreneurship 2000, Upstart Publishing, Chicago.

KPMG/ENSR, 2000, The European Observatory for SMEs; sixth annual report, EIM Business and Policy Research, Zoetermeer.

Krugman, P., 1991, Geography and Trade, MIT Press, Cambridge.

Kuip, I. van der, 1998, Early development of entrepreneurial qualities, Strategic Study B9802, EIM Business and Policy Research, Zoetermeer.

Kuznetz, S., 1966, Modern Economic Growth: Rate, Structure and Spread, Yale University Press, New Haven.

Landes, D.S., 1998, The Wealth and Poverty of Nations; Why Some Are Some So Rich and Some So Poor, Little, Brown and Company, London.

Lever, M.H.C., 1997, The impact of competition on prices and wages in Dutch manufacturing industries, Research Report 9702/E, EIM Business and Policy Research, Zoetermeer.

Lever, M.H.C. and H.R. Nieuwenhuijsen, 1999, The impact of competition on productivity in Dutch manufacturing, in: D.B. Audretsch and A.R. Thurik (eds), Innovation, Industry Evolution, and Employment, Cambridge University Press, Cambridge.

Loscocco, K.A., 1991, Gender and small business success: an inquiry into women's relative disadvantage, Social Forces 70 (1), 65-85.

Loveman, G. and W. Sengenberger, 1991, The re-emergence of small-scale production: an international comparison, Small Business Economics 3 (1), 1-37.

Lucas, R.E., Jr., 1978, On the size distribution of business firms, Bell Journal of Economics 9 (2), 508-523.

Lumpkin, G.T. and G.G. Dess, 1996, Clarifying the entrepreneurial orientation construct and linking it to performance, Academy of Management Review 21 (1), 135-172. 
Lynn, R., 1991, The Secret of the Miracle Economy. Different National attitudes to Competitiveness and Money, Crowley Esmonde Ltd, London.

Meager, N., 1992, Does unemployment lead to self-employment?, Small Business Economics 4 (2), 87-103.

Menkveld, B. and A.R. Thurik, 1999, Firm size and efficiency in innovation, Small Business Economics 12 (1), 97-101.

Minniti, M. and W. Bygrave, 1999, The microfoundations of entrepreneurship, Entrepreneurship: Theory and Practice 23 (4), 41-52.

Mitchell, G.D., 1979, A Dictionary of the Social Sciences, Aldine, New York.

Murphy, K.M., A. Schleifer and R.W. Vishny, 1991, The allocation of talent: implications for growth, Quarterly Journal of Economics, May, 503-530.

Niehof, J., 1999, Barriers for hiring personnel, Research Report 9807/E, EIM Business and Policy Research, Zoetermeer.

Nijsen, A.F.M., 2000, Phases in the recognition of information transfer compliance costs, in: E. Brauchlin and J.H. Pichler (eds), Unternehmer und Unternehmensperspektiven für Klein- und Mittelunternehmen, Duncker and Humblot, Berlin/St. Gallen.

Noorderhaven, N.G., A.R.M. Wennekers, G. Hofstede, A.R. Thurik and R.E. Wildeman, 1999, Selfemployment out of dissatisfaction, Tinbergen discussion paper TI 99-089/3, Erasmus University Rotterdam.

North, D.C., 1994, Economic performance through time, The American Economic Review 84 (3), June 1994.

North, D.C., 1990, Institutions, Institutional Change, and Economic Performance, Cambridge University Press, Cambridge.

OECD, 2000, OECD Employment Outlook, OECD, Paris.

OECD, 1998a, Fostering Entrepreneurship, the OECD jobs strategy, OECD, Paris.

OECD, 1998b, Women Entrepreneurs in Small and Medium Enterprises, OECD Conference Paris 1997, OECD, Paris.

OECD, 1996, SMEs: Employment, Innovation and Growth: The Washington Workshop, OECD, Paris.

Olson, M., 1996, Big bills left on the sidewalk: why some nations are rich, and others poor, Journal of Economic Perspectives 10 (2), Spring, 3-24.

Olson, M., 1982, The Rise and Decline of Nations: Economic Growth, Stagflation and Social Rigidities, Yale University Press, New Haven/London.

Parker, S.C., 1996, A time series model of self-employment under uncertainty, Economica 63 (251), 459-475.

Peters, M., R.C. Cressy and D.J. Storey, 1999, The Economic Impact of Ageing on Entrepreneurship and SMEs, Warwick Business School/EIM, Warwick/Zoetermeer.

Piore, M.J. and C.F. Sabel, 1984, The Second Industrial Divide Possibilities for Prosperity, Basic Books, New York.

Praag, M.C. van, 1999, Some classic views on entrepreneurship, De Economist 147 (3), 311-335.

Praag, M.C. van, 1996, Determinants of successful entrepreneurship, Thesis Publishers, Amsterdam.

Praag, M.C. van and H. van Ophem, 1995, Determinants of willingness and opportunity to start as an entrepreneur, Kyklos 48, 513-540.

Rees, H. and A. Shah, 1986, An empirical analysis of self- employment in the UK, Journal of Applied Econometrics 1 (1), 95-108.

Reynolds, P.D., 2000, Netherlands nascents: entrepreneurship in northern Europe, in EIM/EZ (eds), Entrepreneurship in the Netherlands; opportunities and threats to nascent entrepreneurship, EIM Business and Policy Research, Zoetermeer.

Reynolds, P.D., M. Hay and S.M. Camp, Global Entrepreneurship Monitor: 1999 Executive Report, Babson College, London Business School and the Kauffman Center for entrepreneurial leadership.

Reynolds, P.D., B. Miller and W.R. Maki, 1995, Explaining regional variation in business births and deaths: U.S. 1976-88, Small Business Economics 7 (5), 389-407.

Reynolds, P.D., D.J. Storey and P. Westhead (eds), 1994, Regional variations in new firm formation, Regional Studies, Special Issue, vol. 28, 4, 443-456.

Riding, A.L. and C.S. Swift, 1990, Women business owners and terms of credit: some empirical findings of the Canadian experience, Journal of Business Venturing 5 (5), 327-340.

Rietz, A. du and M. Henrekson, 2000, Testing the female underperformance hypothesis, Small Business Economics 14 (1), 1-10.

Robbins, S.P., 1998, Organizational Behavior: concepts, controversies and applications, Prentice Hall, Englewood Cliffs, New Jersey.

Rosa, P., S. Carter and D. Hamilton, 1996, Gender as a determinant of small business performance: insights from a British study, Small Business Economics 8 (6), 463-478.

Rosa, P, D. Hamilton, S. Carter and H. Burns, 1994, The impact of gender on small business management: preliminary findings of a British study, International Small Business Journal 12 (3), 25-32. 
Sahlman, W.A. and H.H. Stevenson, 1991, Introduction, in: W.A. Sahlman and H.H. Stevenson (eds), The Entrepreneurial Venture. McGraw-Hill, Boston.

Schermerhorn, J.R. Jr., J.G. Hunt and R.N. Osborn, 2000, Organizational Behavior, John Wiley and Sons, Inc., New York.

Schneider, S. and J.L. Barsoux, 1997, Managing Across Cultures, Prentice Hall, London.

SER, 1998, Etnisch ondernemerschap, Sociaal-Economische Raad, Den Haag.

Shane, S.A., 1993, Cultural influences on national rates of innovation, Journal of Business Venturing 8 (1), 59-73.

Shapero, A. and L. Sokol, 1982, The social dimensions of entrepreneurship, in: C.A. Kent, D.L. Sexton and K.H. Vesper (eds), Encyclopedia of Entrepreneurship, Prentice-Hall, Englewood Cliffs, 72-90.

Schultz, T.P., 1990, Women's changing participation in the labor force: a world perspective, Economic Development and Cultural Change 38 (3), 457-488.

Sofrova, 1996, Venture capital for SMEs, Dutch SMEs in international perspective, EIM Business and Policy Research, Zoetermeer.

Stanworth, M.J.K. and J. Curran, 1973, Management Motivation in the Smaller Business, Gower Press, London.

Stevenson, L., 1996, The Implementation of an Entrepreneurship Development Strategy in Canada: The Case of the Atlantic Region, Paris: OECD.

Stigter, H.W., 1999, Vrouwelijk ondernemerschap in Nederland 1994-1997, A9821, EIM Business and Policy Research, Zoetermeer.

Stopford, J.M. and C.W.F. Baden-Fuller, 1994, Creating corporate entrepreneurship, Strategic Management Journal 15 (7), 521-536.

Storey, D.J., 1999, Six steps to heaven: evaluating the impact of public policies to support small business in developed economies, in: D.L. Sexton and H. Landström (eds), Handbook of Entrepreneurship, Blackwell: Oxford, 176-194.

Storey, D.J., 1994, Understanding the Small Business Sector, Routledge, London/New York.

Storey, D.J., 1991, The birth of new firms - does unemployment matter? A review of the evidence, Small Business Economics 3 (3), 167-178.

Storper, M. and R. Salais, 1997, Worlds of Production - The action Frameworks of the Economy, Mass [etc], Harvard University Press, Cambridge.

Suarez-Villa, L., 1998, The structures of cooperation: downscaling, outsourcing and the networked alliance, Small Business Economics 10 (1), 5-16.

The Economist: Millennium special edition, Jan. $1^{\text {st }} 1000$ - Dec. $31^{\text {st }} 1999,1999$, Toiling from there to here, $p$. 22.

Thurik, A.R., 1996, Small firms, entrepeneurship and economic growth, in: P.H. Admiraal (ed.), Small Business in the Modern Economy, Basil Blackwell Publishers, Oxford, 126-152.

Thurik, A.R., 1999, Entrepreneurship, industrial transformation and growth, in: G.D. Libecap (ed.), The Sources of Entrepreneurial Activity: Vol. 11, Advances in the Study of Entrepreneurship, Innovation, and Economic Growth, JAI Press, Stamford, 29-65.

Tillaart, H. van den, and E. Poutsma, 1998, Een factor van betekenis: zelfstandig ondernemerschap van allochtonen in Nederland, ITS, Nijmegen.

Veciana, J.M., 1999, Entrepreneurship as a scientific research programme, Revista Europea de Dirección y Economía de la Empresa 8 (3).

Verheul, I. and A.R. Thurik, 2001, Start-up capital: differences between male and female entrepreneurs. 'Does gender matter?', Small Business Economics, forthcoming.

Vivarelli, M., 1991, The birth of new enterprises, Small Business Economics 3 (3), 215-223.

Wagner, J.A. and J.R. Hollenbeck, 1995, Management of Organizational Behavior, Prentice Hall, Englewood Cliffs, New Jersey.

Wennekers, A.R.M., 1992, Personal and collective services: trends, growth factors and role, a synthesis, in: Personal and Collective Services: an International Perspective, Economic Commission for Europe, Discussion Papers 2 (1), United Nations, New York, 1-25.

Wennekers, A.R.M., 1997, The revival of entrepreneurship in the Netherlands, in: P.J.J. Welfens and C. Graack (eds), Technologieorientierte Unternehmensgründungen und Mittelstandspolitik in Europa, Physica-Verlag, Heidelberg, 185-194.

Wennekers, A.R.M. and A.R. Thurik, 1999, Linking entrepreneurship and economic growth, Small Business Economics 13 (1), 27-55.

Whitley, R. (ed.), 1992, European Business Systems; Firms and Markets In Their National Contexts, Sage Publications, London.

Wildeman, R.E., G. Hofstede, N.G. Noorderhaven, A.R. Thurik, W.H.J. Verhoeven and A.R.M. Wennekers, 1999, Self-employment in 23 OECD countries. The role of cultural and economic factors, Research Report 9811/E, EIM Business and Policy Research, Zoetermeer. 
Wit, G. de, 1991, Determinants of Self-Employment, PhD-thesis, Universiteit van Amsterdam.

Wit, G. de, 1993, Models of self-employment in a competitive market, Journal of Economic Surveys 7, 367397.

Wit, G. de and F.A.A.M. van Winden, 1989, An empirical analysis of self-employment in the Netherlands, Small Business Economics 1 (4), 263-284.

Wit, G. de and F.A.A.M. van Winden, 1991, An m-sector, n-group behavioral model of self-employment, Small Business Economics 3 (1), 49-66. 